\title{
Bone secreted factors induce cellular quiescence in prostate cancer cells
}

\author{
Li-Yuan Yu-Lee $\mathbb{i D}^{1,6 *}$, Yu-Chen Lee 2,6 , Jing Pan ${ }^{1}$, Song-Chang Lin², Tianhong Pan ${ }^{3}$, Guoyu Yu², \\ David H. Hawke $\mathbb{1}^{4}$, Bih-Fang Pan ${ }^{4} \&$ Sue-Hwa Lin $\mathbb{1}^{2,5^{*}}$
}

Disseminated tumor cells (DTCs) undergo a dormant state in the distant metastatic site(s) before becoming overt metastatic diseases. In prostate cancer ( $\mathrm{PCa}$ ), bone metastasis can occur years after prostatectomy, suggesting that bone may provide dormancy-inducing factors. To search for these factors, we prepared conditioned media (CM) from calvariae. Using live-cell imaging, we found that Calvarial-CM treatment increased cellular quiescence in C4-2B4 PCa cells. Mass spectrometry analysis of Calvarial-CM identified 132 secreted factors. Western blot and ELISA analyses confirmed the presence of several factors, including DKK3, BMP1, neogenin and vasorin in the Calvarial-CM. qRT-PCR analysis of total calvariae versus isolated osteoblasts showed that DKK3, BMP1, vasorin and neogenin are mainly expressed by osteoblasts, while MIA, LECT1, NGAL and PEDF are expressed by other calvarial cells. Recombinant human DKK3, BMP1, vasorin, neogenin, MIA and NGAL treatment increased cellular quiescence in both C4-2b and C4-2B4 PCa cells. Mechanistically, DKK3, vasorin and neogenin, but not BMP1, increased dormancy through activating the p38MAPK signaling pathway. Consistently, DKK3, vasorin and neogenin failed to induce dormancy in cells expressing dominant-negative p38 $\alpha$ MAPK while BMP1 remained active, suggesting that BMP1 uses an alternative dormancy signaling pathway. Thus, bone secretes multiple dormancy-inducing factors that employ distinct signaling pathways to induce DTC dormancy in bone.

The majority of men who die of prostate cancer (PCa) have bone metastasis ${ }^{1}$. Bone metastasis can occur years or decades after prostatectomy ${ }^{2}$, suggesting that disseminated tumor cells (DTCs) had been dormant at the metastatic site in bone ${ }^{3}$. Tumor dormancy is now been considered a critical step in the process of metastatic progression during which tumor cells escape therapies that target tumor cells. Dormant tumor cells can become a significant problem at a later time when tumor cells exit dormancy.

Tumor dormancy can be due to instrinsic properties of tumor cells ${ }^{4}$ or due to tumor microenvironment that provides conditions for tumor cells to enter into a quiescent state ${ }^{3}$. In PCa, the bone microenvironment likely plays a critical role in tumor dormancy as bone is the major site of tumor recurrence. How the bone microenvironment promotes DTCs to enter a transient dormant state in bone remains unclear. It is likely that dormancy versus progression of PCa in bone depends on the dynamic interactions between PCa cells and cellular components in bone ${ }^{5}$. Using intravital microscopy, Lawson et al. ${ }^{6}$ showed that myeloma cells are dormant when they are in close proximity with the endosteal bone surface in the tibia, but reactivate when they move further away from bone. Wang et al. ${ }^{7}$ showed that PCa cells that home to bone are frequently associated with osteoblast lineage cells. Thus, it is likely that the bone microenvironment, especially osteoblasts, are providing dormancy-inducing factors.

Identification of factors in the bone microenvironment that promote tumor dormancy will be an important step in delineating dormancy mechanisms. Two members of the TGF/BMP family, GDF10 (BMP-3b) and

\footnotetext{
${ }^{1}$ Department of Medicine, Baylor College of Medicine, Houston, Texas, 77030, United States of America. ${ }^{2}$ Department of Translational Molecular Pathology, The University of Texas M. D. Anderson Cancer Center, Houston, Texas, 77030, United States of America. ${ }^{3}$ Department of Orthopedic Oncology, The University of Texas M. D. Anderson Cancer Center, Houston, Texas, 77030, United States of America. ${ }^{4}$ The Proteomics and Metabolomics Facility, The University of Texas M. D. Anderson Cancer Center, Houston, Texas, 77030, United States of America. ${ }^{5}$ Department of Genitourinary Medical Oncology, The University of Texas M. D. Anderson Cancer Center, Houston, Texas, 77030, United States of America. ${ }^{6}$ These authors contributed equally: Li-Yuan Yu-Lee and Yu-Chen Lee. *email:yulee@bcm.edu; slin@mdanderson.org
} 
Harvest newborn mouse calvariae
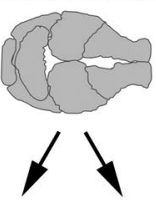

Incubate in

BGJb medium PMO isolation for $48 \mathrm{~h}$

$\downarrow$
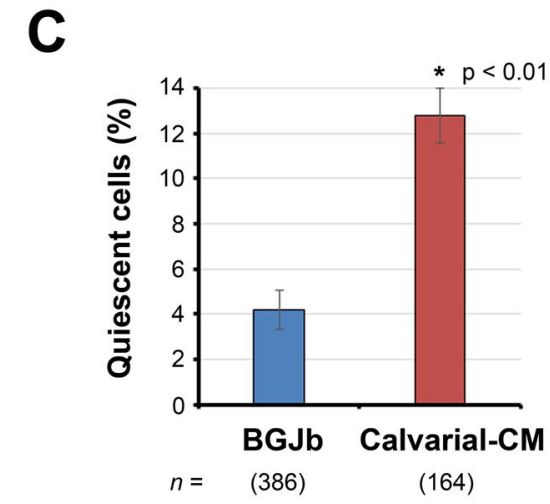

Calvarial-CM

B
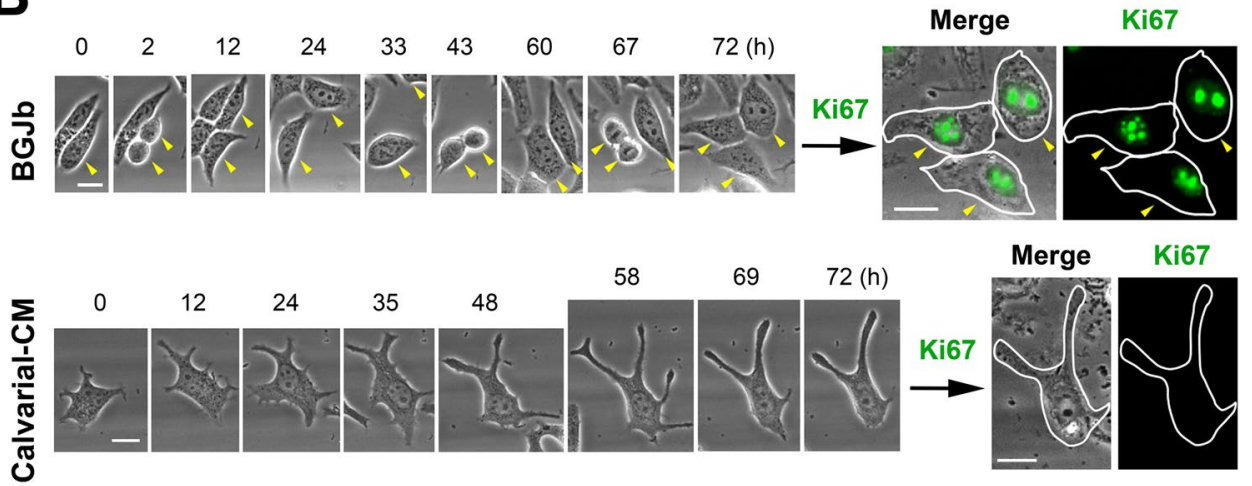

Figure 1. Calvarial conditioned medium (Calvarial-CM) confers cellular quiescence to C4-2B4 PCa cells. (A) Calvariae prepared from 2-5 day-old newborn mice were cultured in BGJb medium containing $0.1 \%$ BSA for $48 \mathrm{~h}$ to generate Calvarial-CM. Calvariae were also used to isolate primary mouse osteoblasts (PMOs) (see details in Materials and Methods). (B) Live-cell imaging analysis of C4-2B4 PCa cells incubated in media containing control BGJb media or Calvarial-CM. Single cells were monitored on a Nikon BioStation and images were acquired every $20 \mathrm{~min}$ for $72 \mathrm{~h}$. (Left) Phase contrast brightfield images. Arrowheads follow one control cell through three cell divisions. Round cells are undergoing mitosis. Note that one daughter cell left the field of view after $\mathrm{T}=33 \mathrm{~h}$. (Right) Immunofluorescence images. Immediately following time-lapse, cells were fixed and immunostained for the proliferation marker Ki67 and re-imaged on the BioStation. Phase contrast images are merged with immunofluorescence images for Ki67. Cell outlines are traced for ease of view. All bars, $20 \mu \mathrm{m}$. (C) Quantification of \% quiescent C4-2B4 cells that did not divide over $72 \mathrm{~h}$ relative to total cells examined (mean \pm s.e.m.). $n$, number of cells monitored. $\mathrm{N}$, number of independent experiments for control BGJb $(\mathrm{N}=5)$, Calvarial-CM $(\mathrm{N}=4)$. P values were by $t$ test.

TGF32, secreted from differentiated osteoblasts, have been reported to induce PCa cells to become quiescent in vitro ${ }^{3}$. Recently, Wnt5a, an osteoblast secreted factor that maintains hematopoietic stem cells in a quiescent state, was found to also promote PCa cell dormancy in bone ${ }^{8}$. In addition, Shiozawa et al.$^{9,10}$ showed that GAS6, a secreted factor that we have also identified in differentiated osteoblasts ${ }^{3}$, also regulates PCa dormancy in the bone marrow. These studies suggest that osteoblasts are one of the cellular components in the bone marrow that support PCa dormancy.

In this study, we looked for additional bone secreted factors that promote cellular dormancy of PCa cells. We used newborn mouse calvariae, which are enriched with osteoblasts ${ }^{11}$, as our study model and identified secreted proteins in the conditioned media. Several of these bone-secreted factors were examined for their effects on inducing cellular quiescence in PCa cells in vitro and for their signaling pathway(s) that leads to cellular dormancy.

\section{Results}

Calvarial conditioned medium (Calvarial-CM) increases cellular quiescence in C4-2B4 PCa cells. To identify bone secreted proteins, we used newborn mouse calvariae, which are enriched with osteoblasts ${ }^{11}$. Calvariae prepared from 2-5 day old newborn mice were cultured in BGJb medium containing $0.1 \%$ BSA for $48 \mathrm{~h}$ to generate calvarial conditioned medium (Calvarial-CM) (Fig. 1A). We have previously shown that this calvarial organ culture condition supports cell proliferation, calvarial bone formation and osteoblast differentiation ${ }^{12}$. To examine whether the Calvarial-CM contains dormancy-inducing activity for PCa cells, C4-2B4 cells were incubated with media containing either control BGJb media or Calvarial-CM and analyzed by live-cell imaging as 
A

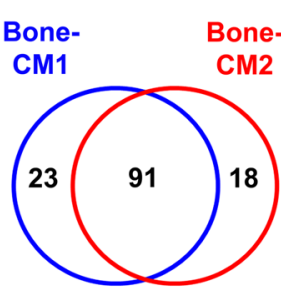

Total: 132 proteins
B

Matrisome Core

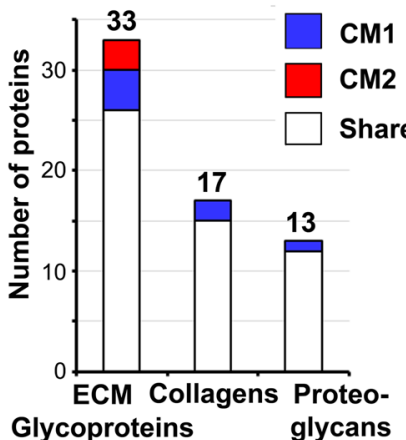

C

Matrisome-Associated

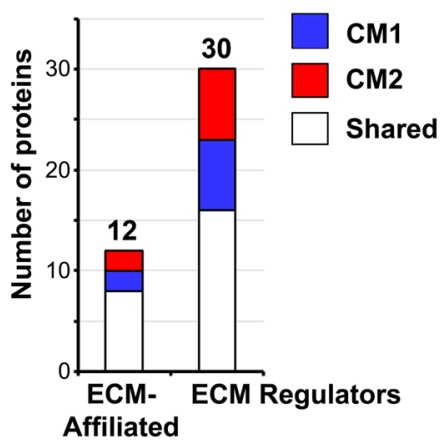

\section{Other Secreted Factors}

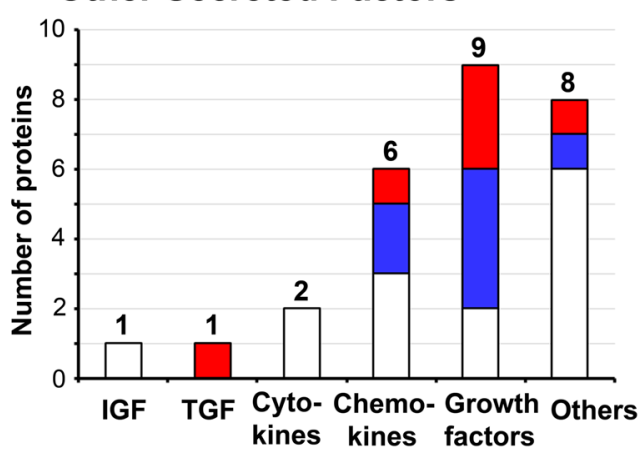

CM1

CM2

Shared

Figure 2. Proteomics analysis of proteins from bone conditioned media. (A) Venn diagram of secreted proteins identified in Bone-CM1 versus Bone-CM2. Two independent batches of Bone-CM were subjected to LC-MS/MS analysis. Proteins were selected using $1 \%$ false discovery rate (FDR). We focused on the secreted proteins and obtained a total of 132 secreted proteins from the Bone-CM. We grouped the 132 secreted proteins into three major categories of extracellular matrix (ECM) proteins according to the Matrisome Project (http://matrisomeproject.mit.edu $)^{15}$. We further curated our list of secreted proteins by searching against the matrisome atlas using the MatrisomeDB2.0 software $^{15,16}$. (B) Matrisome core proteins include ECMglycoportiens, collagens and proteoglycans. (C) Matrisome-associated proteins include ECM-affiliated proteins and ECM regulators. (D) Other secreted factors include growth factors and other proteins. For a complete list of proteins identified in Bone-CM1 $(\mathrm{n}=416)$ and Bone-CM2 $(\mathrm{n}=244)$, see Supplemental Tables S1 and S2.

previously described ${ }^{3}$. Single cells were monitored for cell division over $72 \mathrm{~h}$ on a BioStation ${ }^{3}$. While proliferating cells typically undergo 2-3 cell divisions over $72 \mathrm{~h}$ under our experimental condition, dormant cells are characterized as viable, non-proliferating or slow-cycling ${ }^{3,13,14}$. In C4-2B4 PCa cells incubated in control media, the vast majority of control cells were observed to undergo several rounds of cell division, as illustrated by following one cell from $\mathrm{F} 0(\mathrm{~T}=0 \mathrm{~h})$ as it rounded up to divide into two $\mathrm{F} 1$ progenies $(\mathrm{T}=2 \mathrm{~h})$, which flattened out after cell division, to two more cell divisions into $\mathrm{F} 2(\mathrm{~T}=43 \mathrm{~h})$ and then $\mathrm{F} 3(\mathrm{~T}=67 \mathrm{~h})$ progenies (Fig. $1 \mathrm{~B}$, arrowheads). In contrast, there was a significant increase in the level of non-proliferating quiescent C4-2B4 cells to $12.8 \pm 2.1 \%$ when incubated with Calvarial-CM relative to $4.2 \pm 1.8 \%$ in control BGJb media (Fig. 1C). Immediately following live-cell imaging, cells were stained for the proliferation marker Ki67 and re-imaged on the BioStation. While proliferating cells were positive for Ki67, Calvarial-CM-treated nonproliferating C4-2B4 cells were Ki67 negative (Fig. 1B, right). These observations suggest that the Calvarial-CM contains factors that induced cellular quiescence of C4-2B4 cells.

Secretome analysis of bone conditioned medium (Bone-CM). To identify potential dormancy-inducing factors secreted from calvariae, two independent calvarial preparations cultured in BSA-free medium, referred to as Bone-CM1 and Bone-CM2, to distinguish from Calvarial-CM that contained BSA, were concentrated 20 -fold and analyzed by LC-MS/MS. Using a false discovery rate (FDR) of 1\%, 416 and 244 proteins were identified from Bone-CM1 (Supplemental Table S1) and Bone-CM2 (Supplemental Table S2), respectively. Among these proteins, 114 and 109 proteins are secreted proteins from Bone-CM1 and Bone-CM2, respectively, based on UniProt mouse database. Using the UniProt database, we identified factors that are known to be secreted proteins and additional factors belonging to type I single-pass transmembrane proteins whose extracellular domain can be processed and released as a soluble fragment into the extracellular space. In this manner, 91 proteins were found in both samples, while 23 proteins were additionally found only in Bone-CM1 and 18 only in Bone-CM2 (Fig. 2A). Thus, a total of 132 secreted proteins were identified in the Bone-CM (Table 1). 


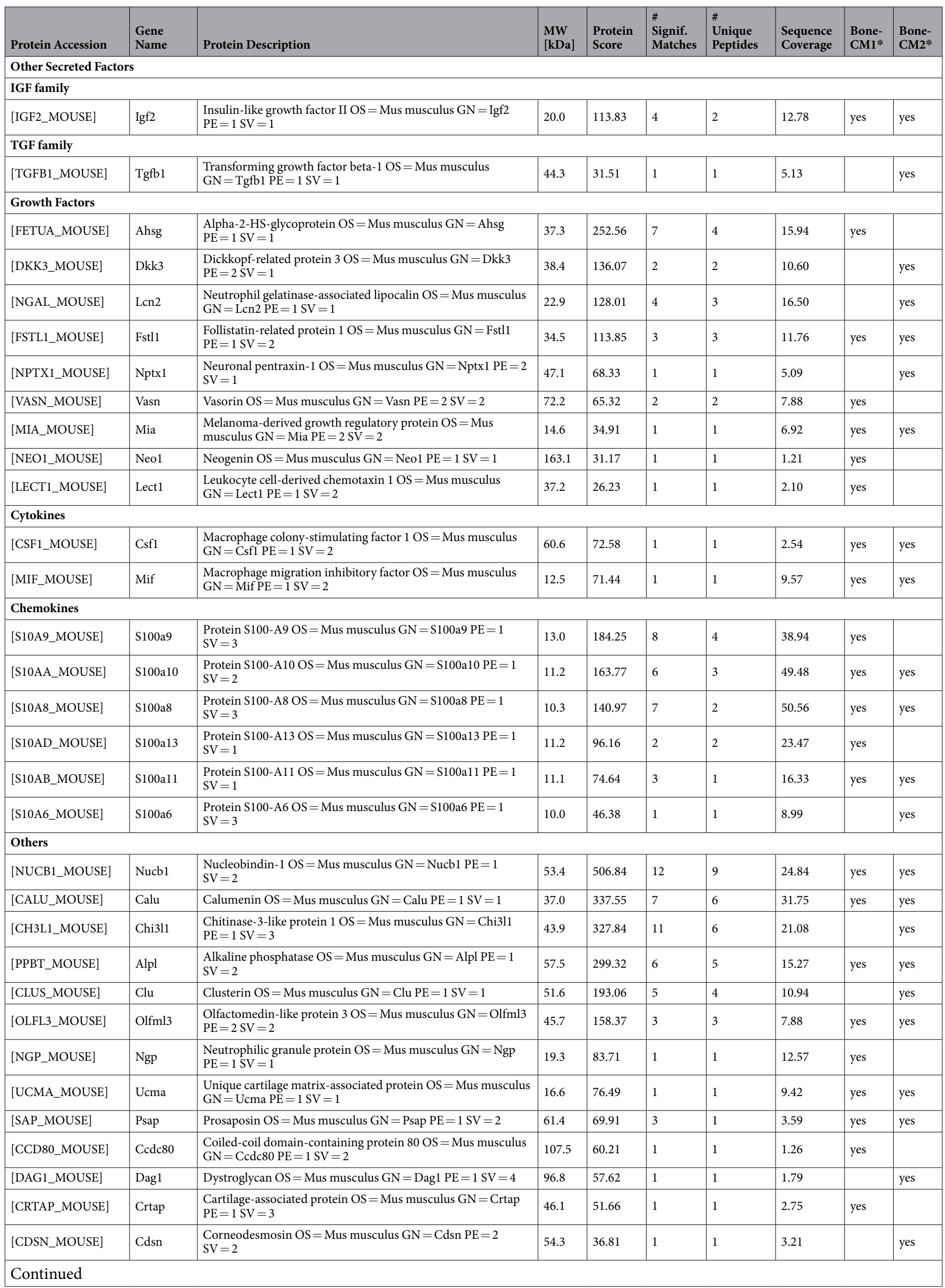




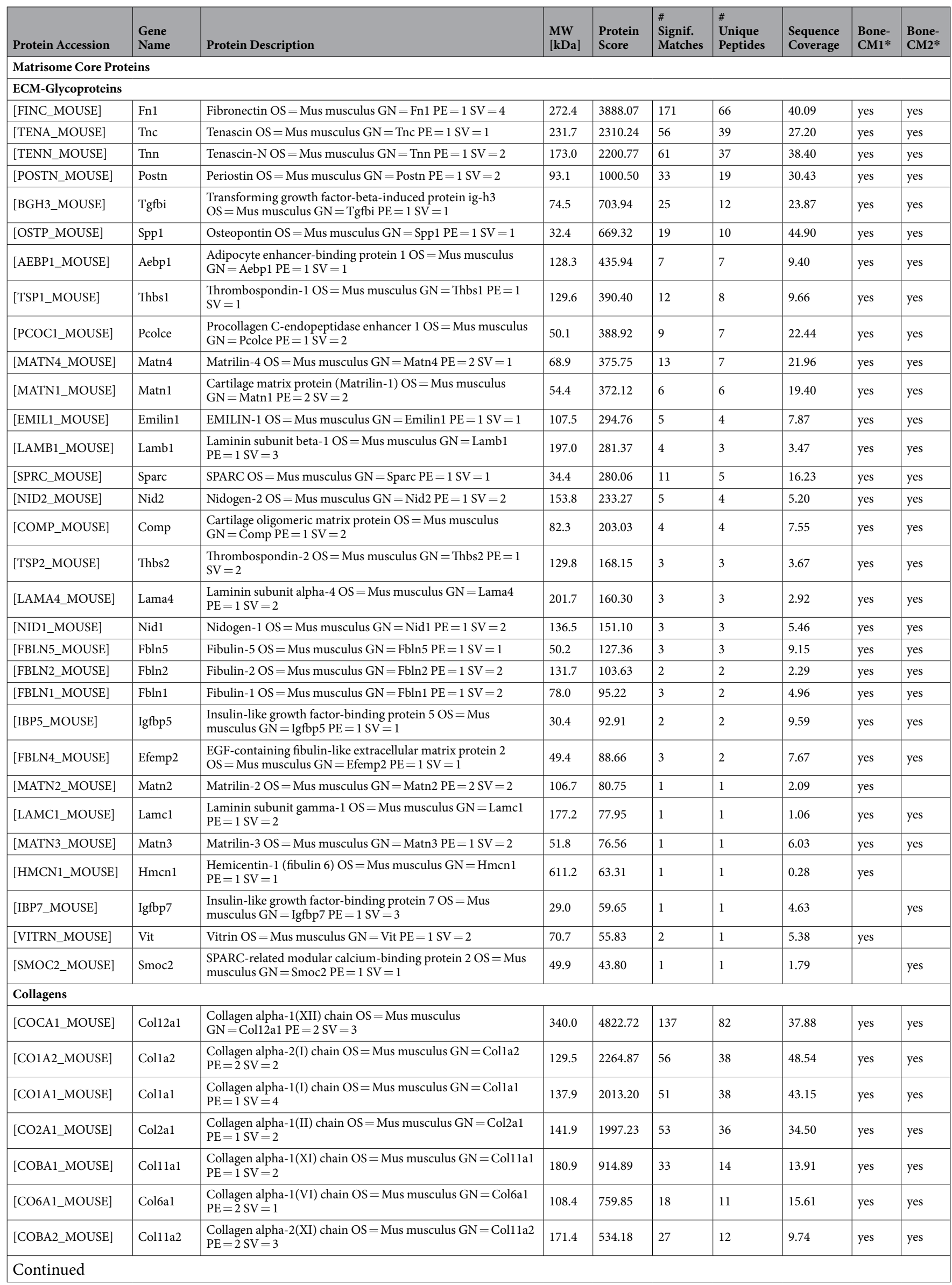




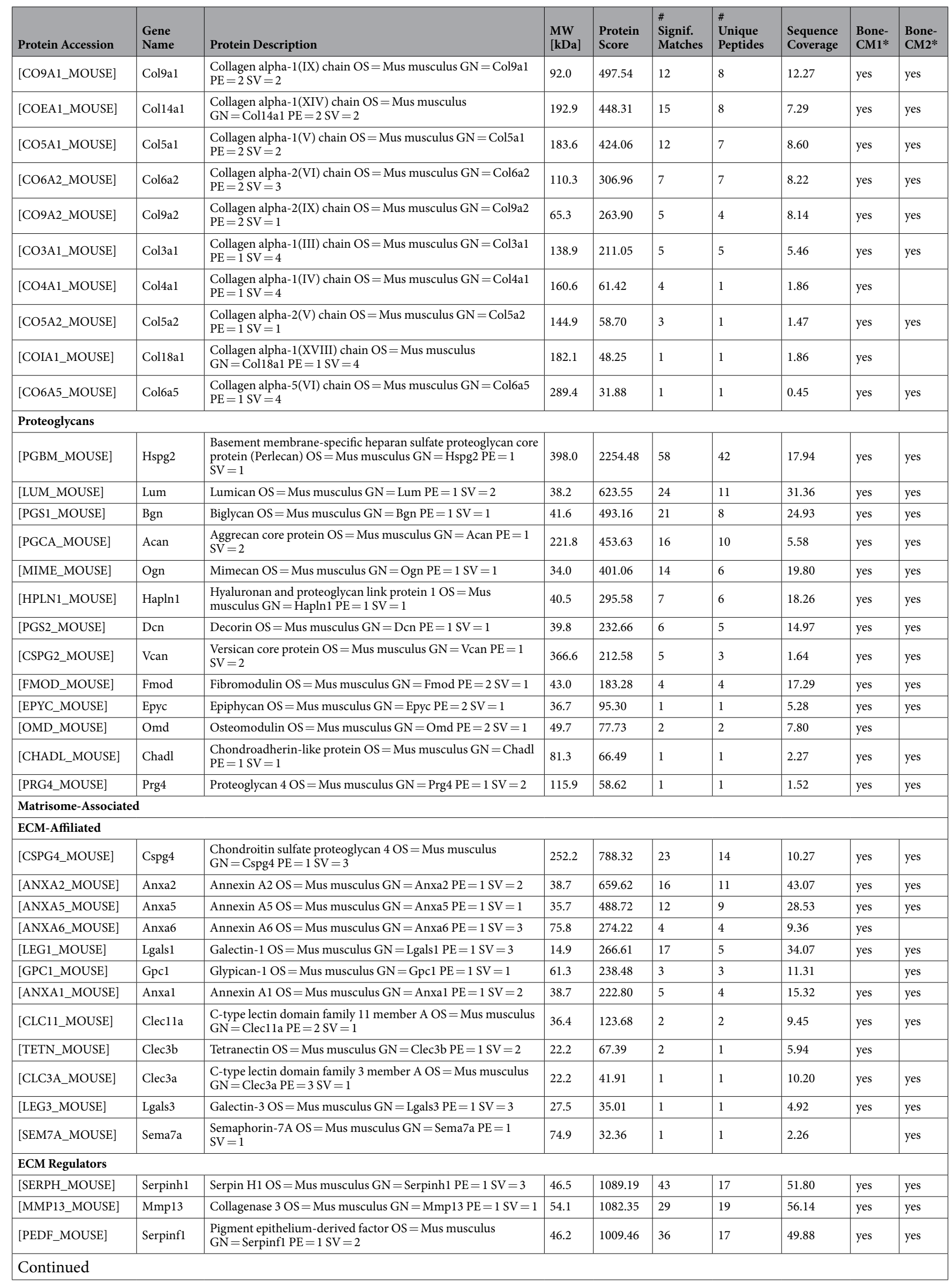




\begin{tabular}{|c|c|c|c|c|c|c|c|c|c|}
\hline Protein Accession & $\begin{array}{l}\text { Gene } \\
\text { Name }\end{array}$ & Protein Description & $\begin{array}{l}\text { MW } \\
{[\mathrm{kDa}]}\end{array}$ & $\begin{array}{l}\text { Protein } \\
\text { Score }\end{array}$ & \begin{tabular}{|l|}
$\#$ \\
Signif. \\
Matches \\
\end{tabular} & \begin{tabular}{|l|}
$\#$ \\
Unique \\
Peptides \\
\end{tabular} & $\begin{array}{l}\text { Sequence } \\
\text { Coverage }\end{array}$ & $\begin{array}{l}\text { Bone- } \\
\text { CM1* }\end{array}$ & $\begin{array}{l}\text { Bone- } \\
\text { CM2* }\end{array}$ \\
\hline [MMP2_MOUSE] & Mmp2 & $\begin{array}{l}72 \mathrm{kDa} \text { type } \mathrm{IV} \text { collagenase } \mathrm{OS}=\text { Mus musculus } \mathrm{GN}=\mathrm{Mmp} 2 \\
\mathrm{PE}=2 \mathrm{SV}=1\end{array}$ & 74.1 & 432.22 & 11 & 8 & 25.83 & yes & yes \\
\hline [MMP3_MOUSE] & Mmp3 & Stromelysin $-1 \mathrm{OS}=$ Mus musculus $\mathrm{GN}=\mathrm{Mmp} 3 \mathrm{PE}=2 \mathrm{SV}=2$ & 53.8 & 401.98 & 11 & 10 & 25.16 & yes & yes \\
\hline [SPA3N_MOUSE] & Serpina3n & $\begin{array}{l}\text { Serine protease inhibitor } \mathrm{A} 3 \mathrm{~N} \text { OS }=\text { Mus musculus } \\
\mathrm{GN}=\text { Serpina3n } \mathrm{PE}=1 \mathrm{SV}=1\end{array}$ & 46.7 & 252.13 & 5 & 4 & 14.83 & yes & yes \\
\hline [CATS_MOUSE] & Ctss & Cathepsin S OS $=$ Mus musculus GN $=$ Ctss $\mathrm{PE}=1 \mathrm{SV}=2$ & 38.4 & 204.21 & 4 & 4 & 13.24 & & yes \\
\hline [CATB_MOUSE] & Ctsb & Cathepsin B OS $=$ Mus musculus GN $=$ Ctsb PE $=1 \mathrm{SV}=2$ & 37.3 & 170.41 & 4 & 3 & 14.16 & yes & yes \\
\hline [ITIH1_MOUSE] & Itihl & $\begin{array}{l}\text { Inter-alpha-trypsin inhibitor heavy chain } \mathrm{H} 1 \mathrm{OS}=\text { Mus } \\
\text { musculus } \mathrm{GN}=\mathrm{It} \text { th } 1 \mathrm{PE}=1 \mathrm{SV}=2\end{array}$ & 101.0 & 136.04 & 3 & 3 & 11.03 & yes & \\
\hline [SPA3C_MOUSE] & Serpina3c & $\begin{array}{l}\text { Serine protease inhibitor } \mathrm{A} 3 \mathrm{C} \mathrm{OS}=\text { Mus musculus } \\
\mathrm{GN}=\text { Serpina } 3 \mathrm{c} \mathrm{PE}=2 \mathrm{SV}=1\end{array}$ & 46.7 & 131.55 & 5 & 1 & 9.35 & yes & yes \\
\hline [GDN_MOUSE] & Serpine2 & $\begin{array}{l}\text { Glia-derived nexin (serpin E) OS }=\text { Mus musculus } \\
\mathrm{GN}=\text { Serpine } 2 \mathrm{PE}=1 \mathrm{SV}=2\end{array}$ & 44.2 & 106.05 & 2 & 2 & 8.06 & & yes \\
\hline [A2MP_MOUSE] & A2mp & $\begin{array}{l}\text { Alpha-2-macroglobulin-P OS }=\text { Mus musculus } \mathrm{GN}=\mathrm{A} 2 \mathrm{mp} \\
\mathrm{PE}=2 \mathrm{SV}=2\end{array}$ & 164.2 & 80.38 & 1 & 1 & 1.49 & yes & yes \\
\hline [CATL1_MOUSE] & Ctsl & Cathepsin L1 OS $=$ Mus musculus GN $=$ Ctsl PE $=1 \mathrm{SV}=2$ & 37.5 & 77.02 & 2 & 2 & 6.59 & yes & yes \\
\hline [ADA15_MOUSE] & Adam 15 & $\begin{array}{l}\text { Disintegrin and metalloproteinase domain-containing protein } \\
15 \mathrm{OS}=\text { Mus musculus } \mathrm{GN}=\text { Adam } 15 \mathrm{PE}=1 \mathrm{SV}=2\end{array}$ & 92.6 & 71.85 & 1 & 1 & 2.66 & & yes \\
\hline [PAI2_MOUSE] & Serpinb2 & $\begin{array}{l}\text { Plasminogen activator inhibitor } 2 \text {, macrophage } \mathrm{OS}=\text { Mus } \\
\text { musculus } \mathrm{GN}=\text { Serpinb2 } \mathrm{PE}=2 \mathrm{SV}=1\end{array}$ & 46.3 & 64.13 & 1 & 1 & 3.37 & & yes \\
\hline [TIMP1_MOUSE] & Timp1 & $\begin{array}{l}\text { Metalloproteinase inhibitor } 1 \mathrm{OS}=\text { Mus musculus } \mathrm{GN}=\text { Timp } 1 \\
\mathrm{PE}=1 \mathrm{SV}=2\end{array}$ & 22.6 & 56.58 & 1 & 1 & 4.39 & yes & yes \\
\hline [MMP12_MOUSE] & Mmp12 & $\begin{array}{l}\text { Macrophage metalloelastase OS }=\text { Mus musculus } \mathrm{GN}=\mathrm{Mmp} 12 \\
\mathrm{PE}=1 \mathrm{SV}=3\end{array}$ & 54.9 & 46.86 & 1 & 1 & 2.54 & & yes \\
\hline [PAI1_MOUSE] & Serpinel & $\begin{array}{l}\text { Plasminogen activator inhibitor } 1 \mathrm{OS}=\text { Mus musculus } \\
\mathrm{GN}=\text { Serpine1 } \mathrm{PE}=1 \mathrm{SV}=1\end{array}$ & 45.1 & 27.19 & 1 & 1 & 7.71 & yes & \\
\hline
\end{tabular}

Table 1. Secretome of mouse calvariae. *Identified in bone-conditioned media Bone-CM1, Bone-CM2, or both as indicated.

Analysis of secreted proteins in bone conditioned medium (Bone-CM). Next, we compared our list of bone-secreted proteins to the extracellular matrix (ECM) protein atlas compiled by the Matrisome Project (http://matrisomeproject.mit.edu $)^{15,16}$. The ECM protein atlas contains an inventory of matrisomes identified from normal lung, liver and colon tissues as well as metastatic colon, melanoma, myeloma and mammary tissues $^{15-18}$, ovary ${ }^{19}$, endothelial cells ${ }^{20}$, pancreatic islet cells ${ }^{21}$, and various stem-cell derived ECMs ${ }^{22}$. According to the classification of the matrisome proteom $\mathrm{e}^{15}$, the 132 bone-secreted proteins can be grouped into three major categories: "Matrisome Core" proteins (63 proteins), "Matrisome-Associated" proteins (42 proteins), and "Other Secreted Factors" (27 proteins). The 63 proteins that belong to the "Matrisome Core" are subgrouped to ECM glycoproteins, collagens and proteoglycans (Fig. 2B). The 42 proteins that belong to the "Matrisome-Associated" category are subgrouped to ECM-affiliated proteins and ECM regulator proteins (Fig. 2C). The rest of the other secreted factors are subgrouped to the IGF, TGF, cytokine, chemokine and growth factor families (Fig. 2D).

Among the 27 other secreted factors, we found that 21 of the bone-secreted proteins have not been identified in other matrisomes. These 21 proteins are listed in Table 2 and include 8 growth factors and 13 other types of secreted factors. Among the growth factors are Dickkopf-related protein 3 (DKK3) ${ }^{23}$, also known as a tumor suppressor ("reduced expression in carcinoma REIC") ${ }^{24-26}$; melanoma-derived growth regulatory protein (MIA) ${ }^{27}$, a factor that inhibits melanoma cell growth and is also known as "cartilage-derived retinoic acid-sensitive protein (CD-RAP)" with a role in cartilage differentiation ${ }^{28}$; and neutrophil gelatinase-associated lipocalin (NGAL) ${ }^{29}$, a factor that promotes renal epithelial cell differentiation. Neogenin (NEO1), a protein that can bind and modulate BMP signaling ${ }^{30,31}$ and is involved in the transition of proliferating cells to their differentiated stat ${ }^{32,33}$; leukocyte cell-derived chemotaxin-1 (LECT1), also known as chrondromodulin, a protein involved in inhibiting the 


\begin{tabular}{|c|c|c|c|c|c|c|c|c|c|}
\hline Protein Accession & $\begin{array}{l}\text { Gene } \\
\text { Name }\end{array}$ & Protein Description & $\begin{array}{l}\text { MW } \\
{[\mathrm{kDa}]}\end{array}$ & $\begin{array}{l}\text { Protein } \\
\text { Score }\end{array}$ & \begin{tabular}{|l|}
$\#$ \\
Signif. \\
Matches
\end{tabular} & \begin{tabular}{|l|}
$\#$ \\
Unique \\
Peptides
\end{tabular} & $\begin{array}{l}\text { Sequence } \\
\text { Coverage }\end{array}$ & $\begin{array}{l}\text { Bone- } \\
\text { CM1* }\end{array}$ & $\begin{array}{l}\text { Bone- } \\
\text { CM2* }\end{array}$ \\
\hline \multicolumn{10}{|l|}{ Growth Factors } \\
\hline [FETUA_MOUSE] & Ahsg & $\begin{array}{l}\text { Alpha-2-HS-glycoprotein OS }=\text { Mus musculus } \\
\text { GN }=\text { Ahsg PE }=1 \mathrm{SV}=1\end{array}$ & 37.3 & 252.56 & 7 & 4 & 15.94 & yes & \\
\hline [DKK3_MOUSE] & Dkk3 & $\begin{array}{l}\text { Dickkopf-related protein } 3 \mathrm{OS}=\text { Mus musculus } \\
\mathrm{GN}=\mathrm{Dkk} 3 \mathrm{PE}=2 \mathrm{SV}=1\end{array}$ & 38.4 & 136.07 & 2 & 2 & 10.60 & & yes \\
\hline [NGAL_MOUSE] & $\operatorname{Lcn} 2$ & $\begin{array}{l}\text { Neutrophil gelatinase-associated lipocalin } \mathrm{OS}=\text { Mus } \\
\text { musculus } \mathrm{GN}=\mathrm{Lcn} 2 \mathrm{PE}=1 \mathrm{SV}=1\end{array}$ & 22.9 & 128.01 & 4 & 3 & 16.50 & & yes \\
\hline [NPTX1_MOUSE] & Nptxl & $\begin{array}{l}\text { Neuronal pentraxin }-1 \mathrm{OS}=\text { Mus musculus } \mathrm{GN}=\mathrm{Nptx} 1 \\
\mathrm{PE}=2 \mathrm{SV}=1\end{array}$ & 47.1 & 68.33 & 1 & 1 & 5.09 & & yes \\
\hline [VASN_MOUSE] & Vasn & Vasorin $\mathrm{OS}=$ Mus musculus $\mathrm{GN}=$ Vasn $\mathrm{PE}=2 \mathrm{SV}=2$ & 72.2 & 65.32 & 2 & 2 & 7.88 & yes & \\
\hline [MIA_MOUSE] & Mia & $\begin{array}{l}\text { Melanoma-derived growth regulatory protein } \\
\mathrm{OS}=\text { Mus musculus } \mathrm{GN}=\mathrm{Mia} \mathrm{PE}=2 \mathrm{SV}=2\end{array}$ & 14.6 & 34.91 & 1 & 1 & 6.92 & yes & yes \\
\hline [NEO1_MOUSE] & Neol & $\begin{array}{l}\text { Neogenin } \mathrm{OS}=\text { Mus musculus } \mathrm{GN}=\mathrm{Neo} 1 \mathrm{PE}=1 \\
\mathrm{SV}=1\end{array}$ & 163.1 & 31.17 & 1 & 1 & 1.21 & yes & \\
\hline [LECT1_MOUSE] & Lect1 & $\begin{array}{l}\text { Leukocyte cell-derived chemotaxin } 1 \mathrm{OS}=\text { Mus } \\
\text { musculus } \mathrm{GN}=\text { Lect1 } \mathrm{PE}=1 \mathrm{SV}=2\end{array}$ & 37.2 & 26.23 & 1 & 1 & 2.10 & yes & \\
\hline \multicolumn{10}{|l|}{ Others } \\
\hline [NUCB1_MOUSE] & Nucb1 & $\begin{array}{l}\text { Nucleobindin-1 OS }=\text { Mus musculus GN }=\text { Nucb } 1 \\
\mathrm{PE}=1 \mathrm{SV}=2\end{array}$ & 53.4 & 506.84 & 12 & 9 & 24.84 & yes & yes \\
\hline [CALU_MOUSE] & Calu & $\begin{array}{l}\text { Calumenin } \mathrm{OS}=\text { Mus musculus } \mathrm{GN}=\text { Calu } \mathrm{PE}=1 \\
\mathrm{SV}=1\end{array}$ & 37.0 & 337.55 & 7 & 6 & 31.75 & yes & yes \\
\hline [CH3L1_MOUSE] & Chi3l1 & $\begin{array}{l}\text { Chitinase-3-like protein } 1 \mathrm{OS}=\text { Mus musculus } \\
\mathrm{GN}=\mathrm{Chi3l1} \mathrm{PE}=1 \mathrm{SV}=3\end{array}$ & 43.9 & 327.84 & 11 & 6 & 21.08 & & yes \\
\hline [PPBT_MOUSE] & Alpl & $\begin{array}{l}\text { Alkaline phosphatase } \mathrm{OS}=\text { Mus musculus } \mathrm{GN}=\mathrm{Alpl} \\
\mathrm{PE}=1 \mathrm{SV}=2\end{array}$ & 57.5 & 299.32 & 6 & 5 & 15.27 & yes & yes \\
\hline [CLUS_MOUSE] & Clu & Clusterin OS $=$ Mus musculus GN $=\mathrm{Clu} \mathrm{PE}=1 \mathrm{SV}=1$ & 51.6 & 193.06 & 5 & 4 & 10.94 & & yes \\
\hline [OLFL3_MOUSE] & Olfml3 & $\begin{array}{l}\text { Olfactomedin-like protein } 3 \mathrm{OS}=\text { Mus musculus } \\
\mathrm{GN}=\mathrm{Olfml} 3 \mathrm{PE}=2 \mathrm{SV}=2\end{array}$ & 45.7 & 158.37 & 3 & 3 & 7.88 & yes & yes \\
\hline [NGP_MOUSE] & Ngp & $\begin{array}{l}\text { Neutrophilic granule protein } \mathrm{OS}=\text { Mus musculus } \\
\mathrm{GN}=\text { Ngp } \mathrm{PE}=1 \mathrm{SV}=1\end{array}$ & 19.3 & 83.71 & 1 & 1 & 12.57 & yes & \\
\hline [UCMA_MOUSE] & Ucma & $\begin{array}{l}\text { Unique cartilage matrix-associated protein } \mathrm{OS}=\text { Mus } \\
\text { musculus } \mathrm{GN}=\mathrm{Ucma} \mathrm{PE}=1 \mathrm{SV}=1\end{array}$ & 16.6 & 76.49 & 1 & 1 & 9.42 & yes & yes \\
\hline [SAP_MOUSE] & Psap & $\begin{array}{l}\text { Prosaposin OS }=\text { Mus musculus } \mathrm{GN}=\text { Psap PE }=1 \\
\mathrm{SV}=2\end{array}$ & 61.4 & 69.91 & 3 & 1 & 3.59 & yes & yes \\
\hline [CCD80_MOUSE] & Ccdc80 & $\begin{array}{l}\text { Coiled-coil domain-containing protein } 80 \mathrm{OS}=\text { Mus } \\
\text { musculus } \mathrm{GN}=\mathrm{Ccdc} 80 \mathrm{PE}=1 \mathrm{SV}=2\end{array}$ & 107.5 & 60.21 & 1 & 1 & 1.26 & yes & \\
\hline [DAG1_MOUSE] & Dag1 & $\begin{array}{l}\text { Dystroglycan } \mathrm{OS}=\text { Mus musculus } \mathrm{GN}=\mathrm{Dag} 1 \mathrm{PE}=1 \\
\mathrm{SV}=4\end{array}$ & 96.8 & 57.62 & 1 & 1 & 1.79 & & yes \\
\hline [CRTAP_MOUSE] & Crtap & $\begin{array}{l}\text { Cartilage-associated protein } \mathrm{OS}=\text { Mus musculus } \\
\mathrm{GN}=\text { Crtap } \mathrm{PE}=1 \mathrm{SV}=3\end{array}$ & 46.1 & 51.66 & 1 & 1 & 2.75 & yes & \\
\hline [CDSN_MOUSE] & Cdsn & $\begin{array}{l}\text { Corneodesmosin } \mathrm{OS}=\text { Mus musculus } \mathrm{GN}=\mathrm{Cdsn} \\
\mathrm{PE}=2 \mathrm{SV}=2\end{array}$ & 54.3 & 36.81 & 1 & 1 & 3.21 & & yes \\
\hline
\end{tabular}

Table 2. Secreted factors unique in bone-conditioned media. *Identified in bone-conditioned media Bone-CM1, Bone-CM2, or both as indicated.

growth of vascular endothelial cells and tumor cells ${ }^{34}$; and vasorin (VASN), a protein that binds to and antagonizes TGF $\beta 1$ signaling ${ }^{35}$, are also found in the list of growth factors (Table 2). Together, these factors are potential candidates in the bone secretome that may play a role in regulating PCa activity in bone.

Biochemical analysis of secreted factors in Calvarial-CM. We used a 20X concentrated BSA-free Calvarial-CM (Bone-CM) for Western blot analysis and examined the expression of five secreted proteins, i.e., BMP1 (110 kDa), DKK3 (38 kDa), MIA (15kDa), NGAL (25 kDa), and PEDF (50kDa). The predicted molecular weight of each protein is indicated in parenthesis. We detected NGAL and PEDF with molecular mass of $25 \mathrm{kDa}$ and $50 \mathrm{kDa}$, respectively, as predicted, in Bone-CM (Fig. 3A). Western blot for BMP1 showed protein bands at $150 \mathrm{kDa}$ and $110 \mathrm{kDa}$. Because BMP1 contains 5 potential N-link glycosylation sites (UniProt database), these results indicate that BMP1 in Bone-CM is likely glycosylated. DKK3 appeared as a major band at $50 \mathrm{kDa}$ and a minor band at $75 \mathrm{kDa}$. As DKK3 also contains 4 potential N-link glycosylation sites (UniProt database), DKK3 in Bone-CM may also be glycosylated. MIA is a small molecular size protein that contains two disulfide bonds (UniProt database). We found that MIA also appeared slightly higher than predicted in three independent blots (see Supplemental Fig. S1), the basis of which is currently unclear. These bands were not detected in control BGJb medium (Fig. 3A), thus confirming the presence of these secreted factors in Bone-CM. Using ELISA, we further determined the concentrations of several bone-secreted factors in two independent mouse Calvarial-CM preparations, Calvarial-CM \# 1 and Calvarial-CM \#2. We found that the Calvarial-CM \#1 and \#2 contains 2.7 and $3.5 \mathrm{ng} / \mathrm{mL}$ BMP1, 7.2 and $14.6 \mathrm{pg} / \mathrm{mL}$ NEO1, 0.2 and $0.6 \mathrm{ng} / \mathrm{mL}$ VASN and 10.5 and $19.4 \mathrm{ng} / \mathrm{mL}$ DKK3, respectively (Fig. 3B). The concentrations of these factors in Calvarial-CM are likely much lower than those in 


\section{A Western blots}

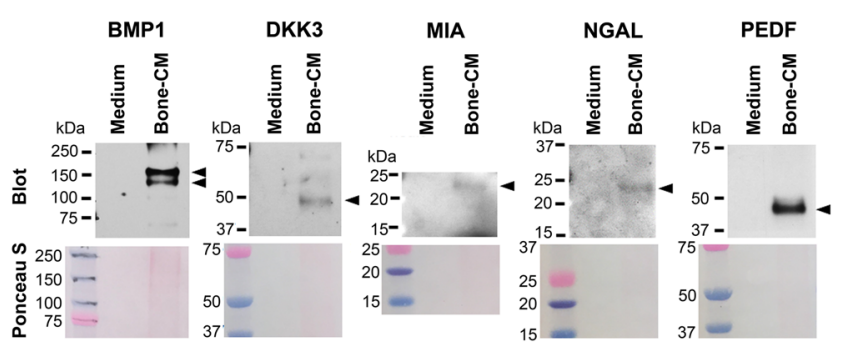

\section{B ELISA}

mBMP1
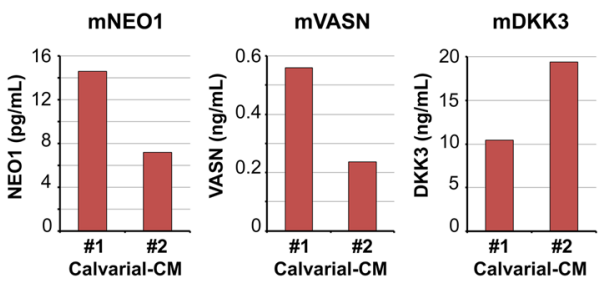

C Real-time qRT-PCR

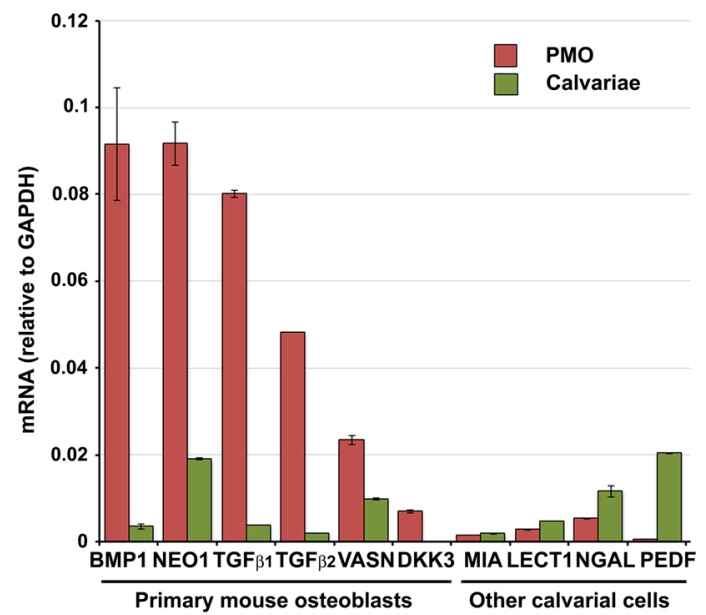

Figure 3. Expression of bone-secreted proteins in the calvariae. (A) Western blots. A 20X concentrated BSAfree Calvarial-CM (Bone-CM) together with a 20X concentrated control BGJb medium were incubated with antibodies against bone-secreted factors as indicated. Original Western blots are shown in Supplemental Fig. S1. (B) ELISA. Protein levels of select bone-secreted factors in two independent preparations of mouse Calvarial-CM, Calvarial-CM \# 1 and Calvarial-CM \#2, were analyzed by ELISA. m, mouse. (C) Real-time qRT-PCR. Total RNAs were prepared from PMO versus total calvariae and analyzed by qRT-PCR. mRNA levels normalized against GAPDH controls were compared between PMO versus calvariae. A higher $\mathrm{PMO}$ to calvariae ratio indicates that the protein is expressed by osteoblasts. Error bars represent triplicate determinations.

physiological or pathological conditions in vivo because in the experimental condition, the bone-secreted factors are secreted into the culture media and are vastly diluted. In contrast, PCa cells may encounter bone-secreted factors in much higher concentrations than the levels we observed by ELISA in the Calvarial-CM because PCa cells are found to be adjacent to the tumor-induced bone $e^{36}$ in the in vivo bone microenvironment. Together, the Western blot and ELISA analyses confirm the presence of candidate bone-secreted factors in Calvarial-CM.

Expression of secreted factors from different types of cells in calvariae. The newborn mouse calvariae contain osteoblasts as well as osteoclasts, osteocytes and fibroblasts. We next determined whether the candidate bone-secreted factors identified by MS/MS are mainly expressed in mouse osteoblasts or other cell types within the calvariae. Primary mouse osteoblasts (PMOs) were isolated from newborn mouse calvariae by digestion with collagenase plus trypsin as described in Materials and Methods (see Fig. 1A). RNA was prepared from PMOs or total calvariae. The expression of the candidate bone-secreted factors in PMOs or calvariae was analyzed by quantitative RT-PCR using mouse-specific primers (Table 3). A higher PMO/calvariae mRNA ratio indicates that a factor is likely to be expressed by osteoblasts. Using this criteria, we found that neogenin, vasorin and DKK3 are mainly expressed in PMOs, while MIA, LECT1 and NGAL are mainly expressed in other cells in the calvariae (Fig. 3C). We also analyzed the expression of two known matrisome-associated ECM regulator 
A

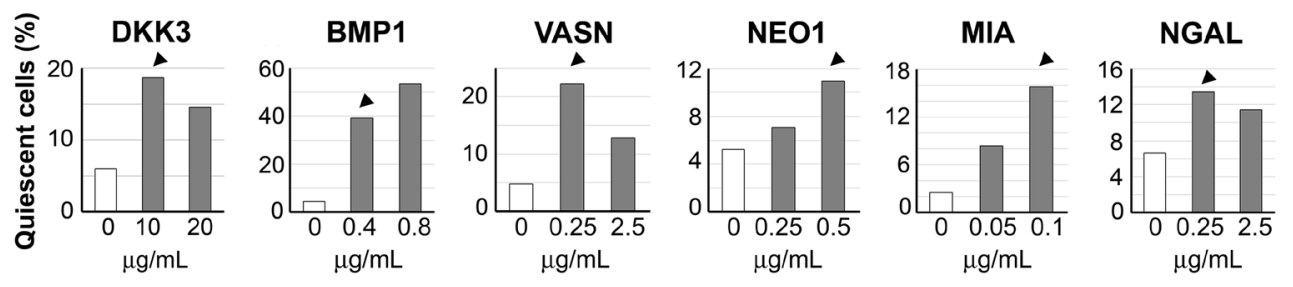

B
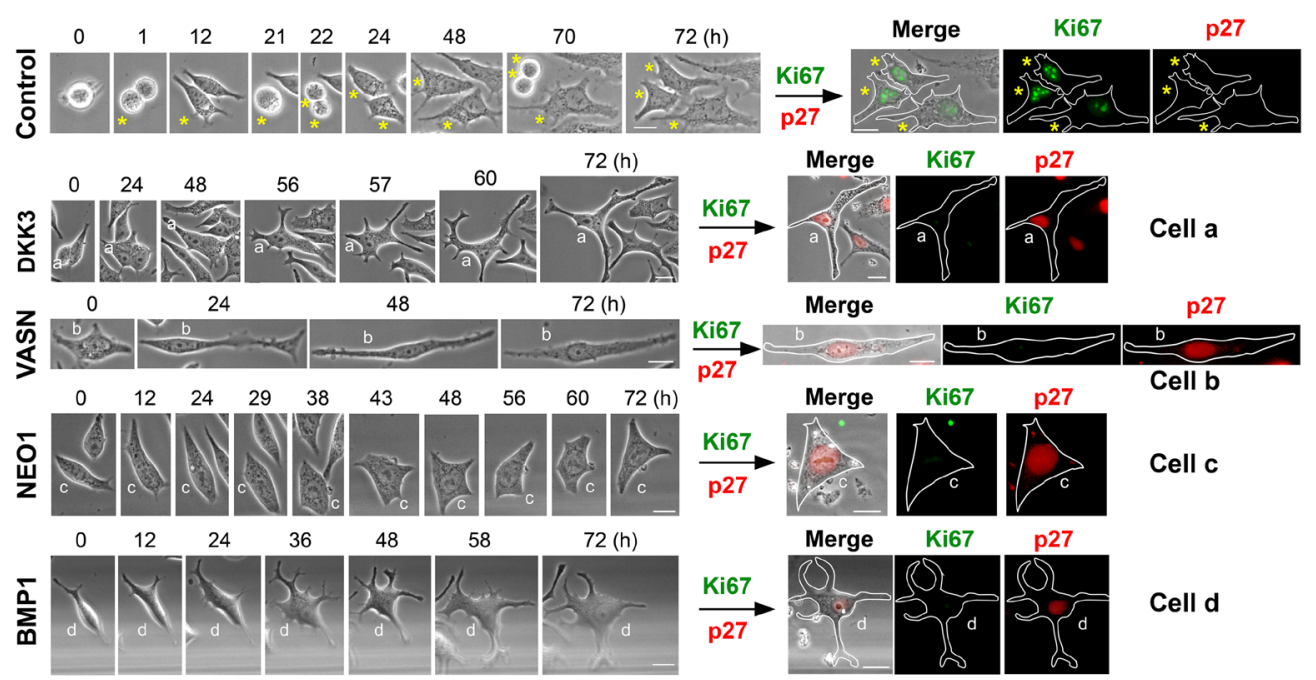

Cell c

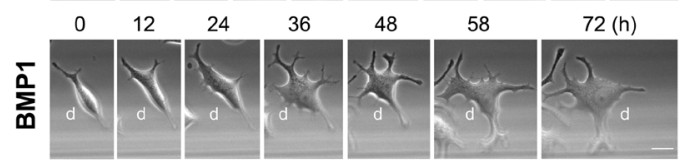

C

C4-2B4

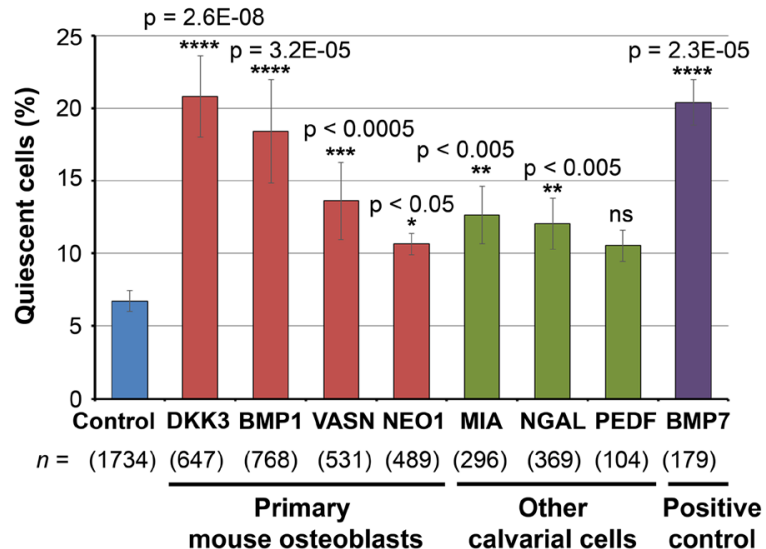

D $\quad$ C4-2b

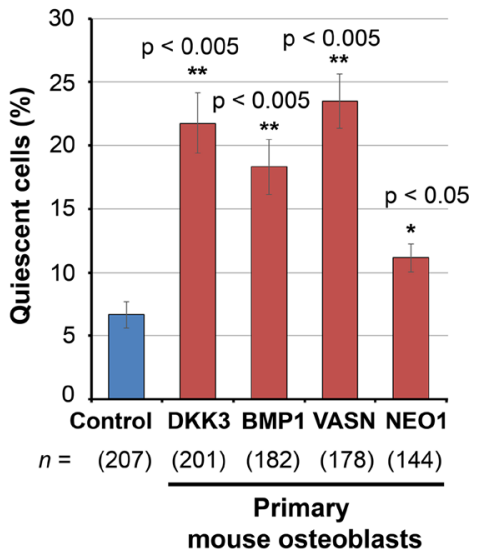

Figure 4. Bone-secreted factors induce cellular quiescence in PCa cells. (A) Dose response. C4-2B4 PCa cells were treated without or with various recombinant human bone-secreted factors at different concentrations and analyzed by live-cell imaging as in Fig. 1. About 100 cells were monitored for each factor at each concentration. Using this approach, we obtained an empirically-derived optimal concentration to be used for each factor (arrowheads): DKK3 $(10 \mu \mathrm{g} / \mathrm{mL})$, BMP1 $(0.4 \mu \mathrm{g} / \mathrm{mL})$, VASN $(0.25 \mu \mathrm{g} / \mathrm{mL})$, NEO1 $(0.5 \mu \mathrm{g} / \mathrm{mL})$, MIA $(0.1 \mu \mathrm{g} / \mathrm{mL})$, and NGAL $(0.25 \mu \mathrm{g} / \mathrm{mL})$. (B) (Left) Phase contrast brightfield images. Cells were plated in a Q4 glass-bottom dish, treated with and without various recombinant proteins, and analyzed by live-cell imaging. Representative images are shown for control cells and cells treated with recombinant human DKK3 (cell a), vasorin (cell b), neogenin (cell c), and BMP1 (cell d). Asterisks (*) follow a control cell through 3 cell divisions. Round cells are cells undergoing mitosis. (Right) Immunofluorescence images. At the end of live-cell imaging, cells were immediately fixed and co-immnostained for Ki67 (proliferation marker) and p27 (dormancy marker), and merged with phase contrast images. Cell outlines are traced for ease of view. All bars, $20 \mu \mathrm{m}$. (C) C4-2B4 cells were treated with various bone-secreted factors, using concentrations as determined in (A), and analyzed by live-cell imaging. PEDF was used at $0.25 \mu \mathrm{g} / \mathrm{ml}{ }^{47}$. The dormancy factor BMP7 $(0.4 \mu \mathrm{g} / \mathrm{ml})^{50}$ was used as a positive control. \% quiescent cells that did not divide relative to total cells counted were quantified (mean \pm s.e.m), except for PEDF and BMP7 (mean \pm s.d.). $n$, number of cells monitored. $\mathrm{N}$, number of independent experiments for control $(\mathrm{N}=24)$, DKK3 $(\mathrm{N}=10), \mathrm{BMP} 1(\mathrm{~N}=10)$, vasorin $(\mathrm{N}=9)$, neogenin $(\mathrm{N}=4), \mathrm{MIA}(\mathrm{N}=4), \mathrm{NGAL}(\mathrm{N}=6), \operatorname{PEDF}(\mathrm{N}=2), \mathrm{BMP}(\mathrm{N}=2)$. P values were by $t$ test. ns, not significant. (D) C4-2b cells were treated with various bone-secreted factors as indicated, monitored by live-cell imaging, and analyzed as in (C). $n$, number of cells monitored. $\mathrm{N}$, number of independent experiments for control $(\mathrm{N}=3)$, DKK3 $(\mathrm{N}=3)$, BMP1 $(\mathrm{N}=3)$, vasorin $(\mathrm{N}=2)$, neogenin $(\mathrm{N}=2)$. P values were by $t$ test. 
C4-2B4
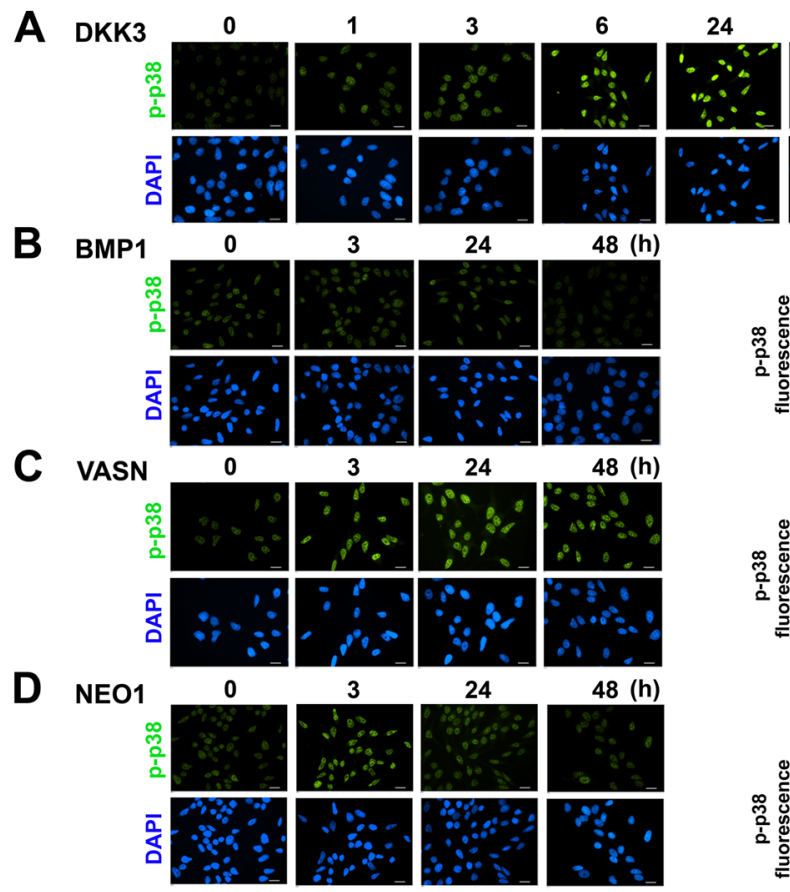

$48(\mathrm{~h})$
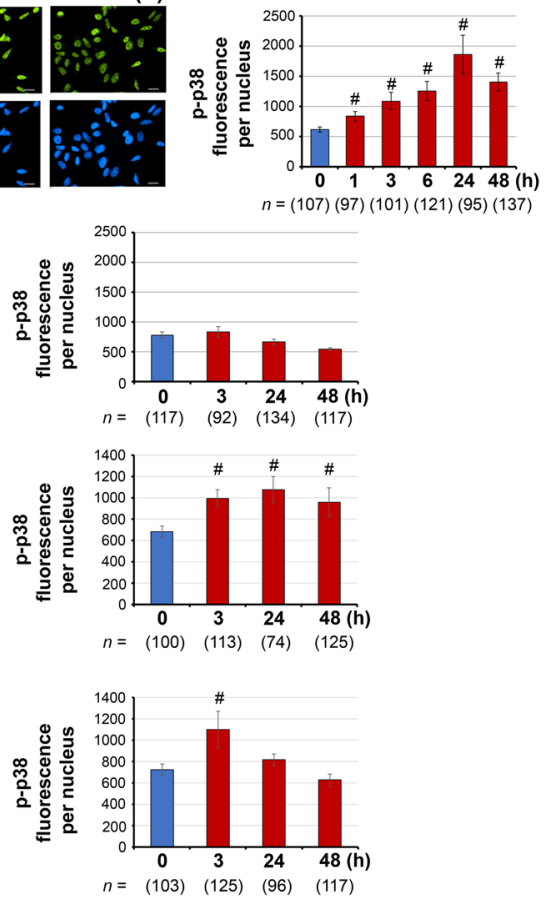

C4-2b
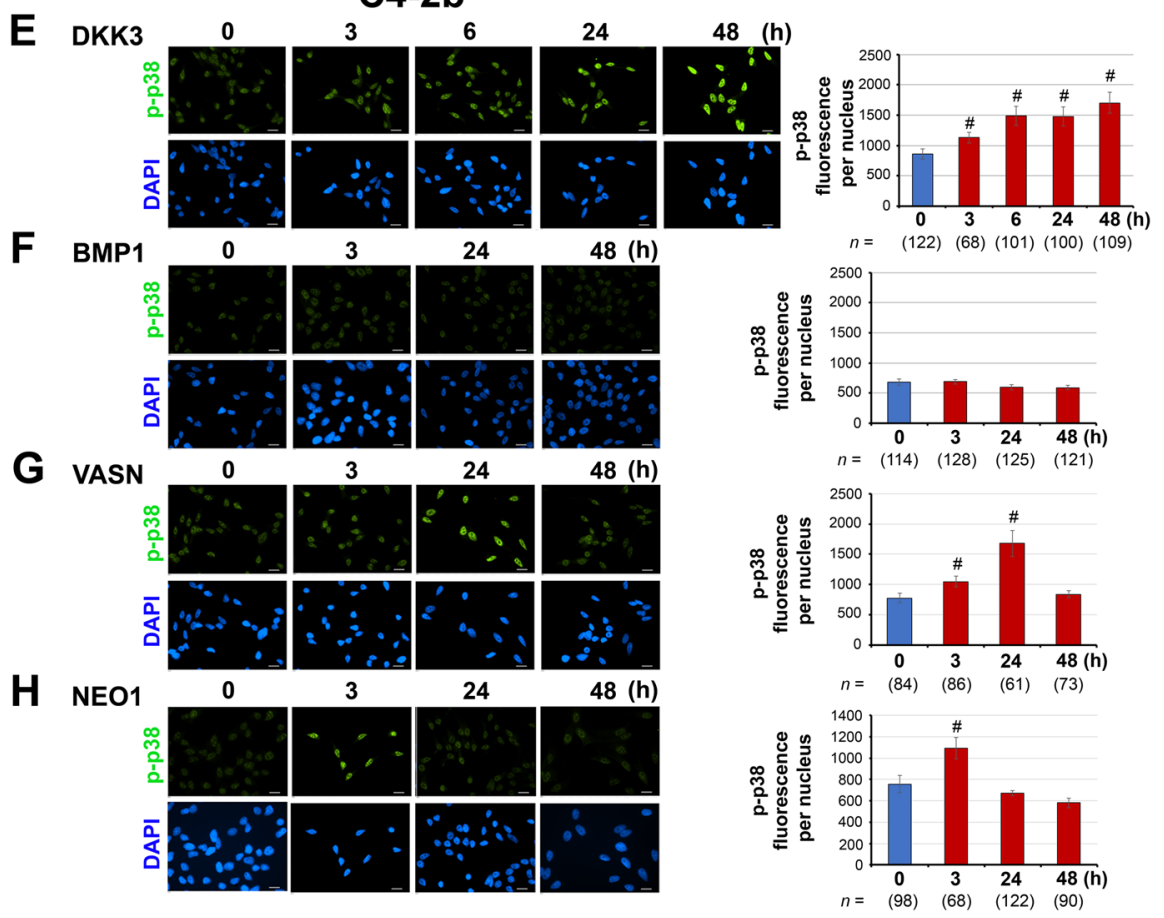

Figure 5. Dormancy signaling via phospho-p38MAPK. C4-2B4 (A-D) and C4-2b (E-H) cells were incubated with select bone-secreted factors over a time course for up to $48 \mathrm{~h}$ as indicated. Cells at different time points were immunostained for phospho-p38MAPK (p-p38) and counterstained with DAPI for DNA. Representative images of p-p38 nuclear translocation are shown. The levels of p-p38 fluorescence signals per nucleus were quantified using NIS-Elements software. All bars, $20 \mu \mathrm{m}$. $n$, number of nuclei analyzed. P values were by $t$ test. $\# \mathrm{p}<0.0001$.

proteins that have important functions in bone: BMP1, a metalloproteinase that regulates the formation of the bone matrix $\mathrm{x}^{37,38}$, and pigment epithelium-derived factor (PEDF), a potent antiangiogenesis factor ${ }^{39}$ that was also shown to promote osteoblast differentiation and mineralization of the bone matrix (Table 1$)^{40}$. We found that BMP1 is mainly expressed in PMOs while PEDF is expressed by other cells in the calvariae (Fig. 3C). As controls 
for known osteoblast-expressed proteins, we showed that two TGF $\beta$ family members TGF $\beta 1$ and TGF $\beta 2$ are expressed by PMOs. TGF 32 was previously shown to be a dormancy-inducing factor while TGF $\beta 1$ was not t $^{3,14}$. TGF $\beta 1$ also did not affect cellular dormancy in HNSCC HEp3 cells $s^{14}$, breast cancer cells ${ }^{20}$ or PCa cells ${ }^{3}$.

Dormancy-inducing activity of bone-secreted factors. To examine the potential dormancy-inducing activity of candidate bone-secreted factors, recombinant proteins corresponding to select factors were first screened for their ability to induce cellular quiescence in PCa cells. We conducted a dose response analysis for each selected bone-secreted factors. We used factor concentrations reported in the literature ${ }^{41-47}$ and tested several concentrations to ensure that the dosages used do not cause toxicity, i.e., cell death, in PCa cells using live-cell imaging. Based on the response, we selected the following concentrations for further study: DKK3 (10 $\mu \mathrm{g} /$ $\mathrm{mL})$, BMP1 $(0.4 \mu \mathrm{g} / \mathrm{mL})$, vasorin $(0.25 \mu \mathrm{g} / \mathrm{mL})$, neogenin $(0.5 \mu \mathrm{g} / \mathrm{mL})$, MIA $(0.1 \mu \mathrm{g} / \mathrm{mL})$, or NGAL $(0.25 \mu \mathrm{g} / \mathrm{mL})$ (Fig. 4A, arrowheads). Live-cell imaging showed that there was an increase in non-dividing quiescent cells when C4-2B4 cells were incubated with recombinant human DKK3, vasorin, neogenin or BMP1 (Fig. 4B, left), as illustrated by examples of cells that exhibited a "dormant" phenotype after treatment with DKK3 (cell a), vasorin (cell b), neogenin (cell c), or BMP1 (cell d). In contrast, the majority of control C4-2B4 PCa cells underwent several rounds of cell division, as illustrated by following one cell from F0 (T=0 h) as it divided into F1 $(\mathrm{T}=1 \mathrm{~h})$, $\mathrm{F} 2(\mathrm{~T}=22 \mathrm{~h})$ and then $\mathrm{F} 3(\mathrm{~T}=70 \mathrm{~h})$ progenies (Fig. 4B, asterisks). Of note, although these non-proliferating quiescent cells did not divide, they exhibited a low level of movement with cell shape changes during time-lapse recording (Fig. 4B, left).

We further confirmed the dormancy status of the non-dividing quiescent cells by co-immunostaining for Ki67 and p27. Proliferating cells express the proliferation marker Ki67 in all phases of the cell cycle (G1, S, G2, M) but not during quiescence (G0). In quiescent breast cancer cells, the cell cycle inhibitor p27 has been shown to be upregulated and translocated into the nucleus ${ }^{48,49}$. Thus, cellular dormancy is characterized by Ki67 negativity and p27 positivity. Control cells that underwent several rounds of cell division over $72 \mathrm{~h}$ were found to be Ki67 positive and p27 negative (Fig. 4B, right). In contrast, quiescent cells a - $\mathrm{d}$ that did not divide upon treatment with DKK3, vasorin, neogenin or BMP1 were Ki67 negative and showed nuclear translocation of p27 (Fig. 4B, right). The combination of these morphological, cell cycle and biochemical analyses suggests that DKK3, vasorin, neogenin and BMP1 induced cell cycle arrest leading to cellular dormancy in C4-2B4 cells.

The levels of dormancy induced by the select bone-factors were quantified directly by cell counting. By combining 72 independent live-cell imaging experiments, around 1,700 control cells and 3,500 cells treated with various recombinant factors were monitored at the single cell level (Fig. 4C). Amongst the selected factors, we found that DKK3 significantly increased the level of quiescent, non-dividing C4-2B4 cells by about 3-fold, to 20\% when compared to 7\% in untreated control cells (Fig. 4C). This level of DKK3-mediated dormancy induction was comparable to that observed with the dormancy-inducing factor $\mathrm{BMP}^{50}$, which was used as a positive control. Two other factors, vasorin and neogenin, were also effective in inducing cellular quiescence, though to a lesser extent than DKK3. Of the three factors expressed by other calvarial cells, MIA and NGAL exerted a modest effect on cellular quiescence on C4-2B4 cells while PEDF effects did not reach stastistical significance relative to control cells. BMP1, which differs from BMP2 - BMP16 in that it is not a TGF $\beta$-like protein, but is important for the formation and mineralization of bone ${ }^{38,51}$, was found to induce a significant $18 \%$ of $\mathrm{C} 4-2 \mathrm{~B} 4$ cells to become quiescent. These analyses show that a variety of bone-secreted factors display different extent of dormancy-inducing activity on C4-2B4 cells.

We tested the dormancy-inducing activity of bone-secreted factors on another PCa cell line C4-2 $\mathrm{b}^{52}$. Although C4-2b and C4-2B4 cells are both sublines derived from LNCaP cells ${ }^{53,54}$, we previously observed that these cells show differences in cell morphology and motility under the same culture conditions ${ }^{3}$. That C4-2b and C4-2B4 cells have distinct properties is supported by recent reports that these cells exhibit differences in their epithelial-to-mesenchymal transition state ${ }^{55}$. We found that DKK3, BMP1 and vasorin induced significant cellular quiescence to $18-24 \%$ relative to $7 \%$ in control untreated C4-2b cells (Fig. 4D), while neogenin's effects were modest. Taken together, these results show that multiple factors secreted by different cell types within bone can induce cellular dormancy in PCa cells.

Phospho-p38MAPK in dormancy signaling. Activation of p38MAPK through phosphorylation is one of the major signaling pathways utilized by dormancy-inducing factors ${ }^{14,56}$. We examined whether these newly-identified dormancy factors induce dormancy through p38MAPK phosphorylation ${ }^{3}$. Immunofluorescence imaging followed by quantification showed that phospho-p38MAPK (p-p38) became significantly enriched in the nucleus of C4-2B4 cells in response to DKK3 (Fig. 5A), vasorin (Fig. 5C) and neogenin (Fig. 5D) stimulation, indicating that these factors induced p38MAPK activation. Both DKK3 and vasorin stimulated p-p38 nuclear translocation within $3 \mathrm{~h}$ with sustained activation maintained up to $24-48 \mathrm{~h}$ in C4-2B4 cells (Fig. 5A,C), while neogenin stimulated a transient p-p38 nuclear translocation with a maximum at $3 \mathrm{~h}$ followed by a decline to basal levels by $48 \mathrm{~h}$ (Fig. 5D). Interestingly, although BMP1 activated dormancy induction (Fig. 4C), BMP1 did not stimulate p-p38 nuclear translocation in C4-2B4 cells (Fig. 5B), suggesting that an alternative signaling pathway for dormancy induction is used by BMP1. A similar pattern of p-p38 nuclear translocation in response to DKK3 (Fig. 5E), vasorin (Fig. 5G), and neogenin (Fig. 5H) was observed in C4-2b cells. As also observed in C4-2B4 cells, BMP1 did not stimulate p-p38 nuclear translocation in C4-2b cells (Fig. 5F), although BMP1 was effective in stimulating dormancy induction in C4-2b cells (Fig. 4D). These results suggest that DKK3, vasorin and neogenin activated canonical p-p38MAPK dormancy signaling, albeit with differences in the kinetics of p38MAPK activation, and BMP1 employs an alternative signaling pathway to dormancy induction.

Effect of dominant-negative p38 $\mathrm{\alpha MAPK}$ mutant on dormancy-inducing activity of bone-secreted factors. We next examined whether activation of p38MAPK plays a role in mediating the 
dormancy-inducing activity of bone-secreted factors, using PCa cells transduced with a dominant-negative p38 $\alpha$ MAPK $(\mathrm{p} 38 \alpha \mathrm{DN})$ mutant construct ${ }^{3}$. DKK3, vasorin and neogenin were unable to stimulate dormancy induction in C4-2B4-p38 $\alpha$ DN cells (Fig. 6A, lower), while exhibiting dormancy induction in the control C4-2B4-vector cells (Fig. 6A, upper), suggesting that overexpression of $\mathrm{p} 38 \alpha \mathrm{DN}$ effectively blocked dormancy induction by these factors. These results are consistent with an increase in p-p38 nuclear translocation in response to these factors in C4-2B4-vector control cells (Fig. 6B, upper and lower) but not in C4-2B4-p38 $\alpha$ DN cells (Fig. 6B, middle and lower). In contrast, BMP1 continued to elicit dormancy activation in both C4-2B4-Vector control cells (Fig. 6A, upper) as well as C4-2B4-p38 $\alpha$ DN cells (Fig. 6A, lower), in agreement with a lack of p-p38 nuclear translocation (Fig. 6B, middle and lower) in response to BMP1. Similar results were observed when C4-2b cells overexpressing $\mathrm{p} 38 \alpha \mathrm{DN}$ were examined. Dormancy induction by DKK3, vasorin and neogenin was prevented in C4-2b-p38 $\alpha$ DN cells (Fig. 6C, lower), but not in C4-2b-Vector control cells (Fig. 6D, upper). That BMP1 does not signal through $\mathrm{p} 38 \mathrm{MAPK}$ was observed by the lack of p-p38 nuclear translocation in C4-2b-Vector control cells (Fig. 6D) and continued dormancy induction in C4-2b-p38 $\alpha \mathrm{DN}$ cells in the presence of BMP1 (Fig. 6C, lower). These results further confirm that BMP1 mediates dormancy induction independently of p38MAPK. Thus, activation of p38MAPK signaling is required to mediate the dormancy-inducing activity of DKK3, vasorin and neogenin, but not BMP1, in PCa cells.

\section{Discussion}

We have identified a unique set of bone-secreted factors that can induce cellular dormancy in PCa cells. These factors belong to different protein families. While many of these factors are found to be expressed by osteoblasts, some are expressed by other stromal cells in the calvariae. Most of these factors induce cellular dormancy in PCa cells through activation of the p38MAPK signalling pathway, albeit with different kinetics of p38MAPK activation. Interestingly, BMP1-induced cellular dormancy is mediated through a p38MAPK-independent pathway. Thus, dormancy induction from the bone microenvironment involves factors secreted from multiple cell types with various signal transduction mechanisms. Such variations may result in varied dormancy duration seen in the clinical setting. These observations may contribute to the future development of strategies for the prevention or treatment of bone metastasis.

The transforming growth factor- $\beta$ (TGF $\beta$ ) family proteins are the first group of proteins shown to exhibit dormancy-inducing activity ${ }^{57}$. These proteins include TGF $\beta 2^{3,14}$, GDF10 (BMP-3b) ${ }^{3}$, and BMP7 ${ }^{50}$. Other factors that exhibit dormancy-inducing activities include GAS6 ${ }^{9,10}$, thrombospondin (TSP-1) ${ }^{20}$, Wnt $5 \mathrm{a}^{8}$ and LIF ${ }^{58}$. The panel of bone-secreted factors identified in our studies expands this growing family of dormancy-inducing factors. One of the secreted factors is DKK3, a divergent member of the DKK family of secreted Wnt signaling antagonists $^{59}$. Overexpression of DKK3 has been shown to inhibit prostate tumor growth and metastasis by limiting TGF $\beta /$ Smad signaling ${ }^{24,25,60}$. DKK3 was also found to be downregulated in a range of human cancers ${ }^{59,61}$. Interestingly, DKK3 does not seem to act as a Wnt signaling antagonist ${ }^{59,62}$. Recent studies in a bone fracture and repair model using a DKK3-GFP reporter mouse suggest that DKK3 is expressed in the mesenchymal progenitor cells in the periosteum and in the bone marrow and is required for cartilage cell development by blocking osteogenesis $^{63}$. Our studies revealed a potential role for DKK3 as a dormancy-inducing factor that signals through p38MAPK to modulate PCa growth in bone. Vasorin, another bone-secreted factor, is a type I single-pass transmembrane protein ${ }^{35}$ that contains tandem leucine-rich repeats, an epidermal growth factor (EGF)-like motif, and a fibronectin type III-like motif in the extracellular domain, which are motifs involved in protein-protein interactions. It has been shown that the extracellular domain of vasorin can be cleaved into a soluble ectodomain that binds directly to TGF $\beta 1$ and antagonizes TGF $\beta 1$ signaling ${ }^{35,64}$. Although our study showed that vasorin induces PCa cell dormancy through p38MAPK in vitro, whether antagonizing TGF $\beta 1$ signaling contributes in part to how vasorin induces cellular quiescence of PCa cells is unknown. Another dormancy-inducing factor is BMP1. The ECM-regulator BMP1 is a member of the BMP1/Tolloid-like family of metalloproteinase and is found in many matrisomes (Table 1). In bone, BMP1 is highly expressed in areas of bone matrix formation, and mutations in BMP1 result in osteogenesis imperfecta or "brittle bone disease" in humans $s^{51}$. BMP1 is reported to affect BMP/TGF $\beta$ pathways indirectly through the release of latent binding proteins that tether BMP2/4 as well as TGF $\beta 1-3$ in the ECM matrix ${ }^{38,65}$. Our studies showed that BMP1 contributes to dormancy in PCa cells through a p38MAPK-independent pathway. Whether BMP1's metalloproteinase activity is involved in its dormancy-inducing activity is not known.

We note that the empirically-determined concentrations of recombinant factors used in our studies are about 1,000 times higher than those found in Calvarial-CM. As PCa cells are found adjacent to the tumor-induced bone $^{36}$, it is likely that PCa cells may encounter bone-secreted factors in higher concentrations in vivo. Indeed, the high factor concentrations used in our studies are within the range reported in the literature. As an example, similar concentrations of human DKK3 at $10-50 \mu \mathrm{g} / \mathrm{mL}$ were used to block the proliferation of human kidney KPK1 cancer cells ${ }^{41}$; human BMP1-3, an alternatively-spliced variant of BMP1, at 150-1000 ng/mL was observed to increase the expression of p21, a cell cycle inhibitor, in human embryonic kidney 293 (HEK293) cells ${ }^{42}$; human MIA at $50 \mathrm{ng} / \mathrm{mL}$ was used to inhibit the invasive activity of melanoma cells ${ }^{45}$; and PEDF at $250 \mathrm{ng} / \mathrm{mL}$ was used to induce osteoblastic differentiation of human mesenchymal stem cells ${ }^{47}$.

We found that different cell types, besides osteoblasts, within the tumor microenvironment are also involved in the induction of tumor cell dormancy. That bone marrow stromal cells secrete factors to induce cellular dormancy has been previously reported. Kobayashi et al..$^{50}$ showed that HS5 bone marrow stromal cells secrete BMP7 that inhibits PC3 PCa cell proliferation. We also confirmed the dormancy-inducing activity of BMP7 on C4-2B4 PCa cells (Fig. 4C), but found that BMP7 is not expressed by either osteoblasts or other calvarial cells (data not shown). Ghajar et al..$^{20}$ showed that endothelial cells in mature vessels secrete TSP-1 that leads to breast tumor cell dormancy. Price et al. ${ }^{66}$ showed that dormant breast cancer cells are tethered to the bone marrow vascular niche through C-X-C chemokine receptor type 4 (CXCR4) interactions with stromal cell-derived factor (SDF-1) that is 
A

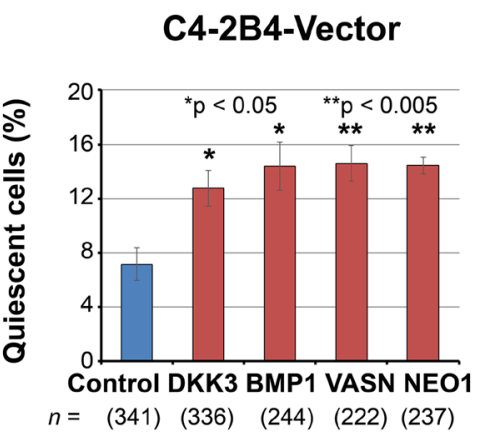

C4-2B4-p38 $\alpha \mathrm{DN}$

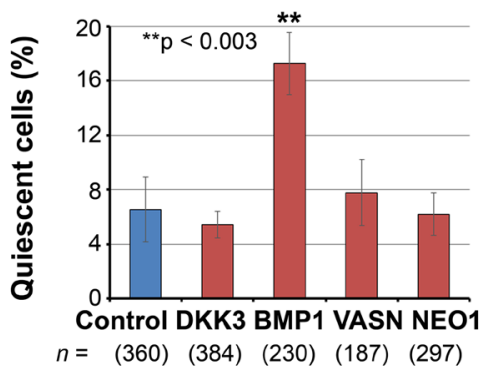

B

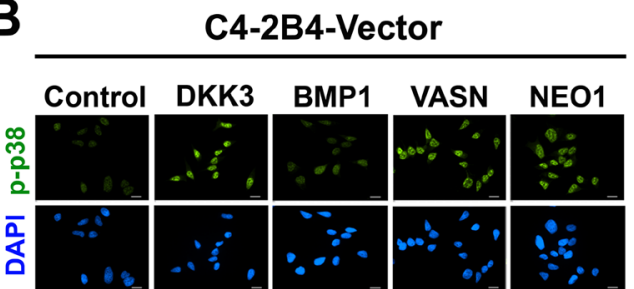

C4-2B4-p38 $\alpha \mathrm{DN}$
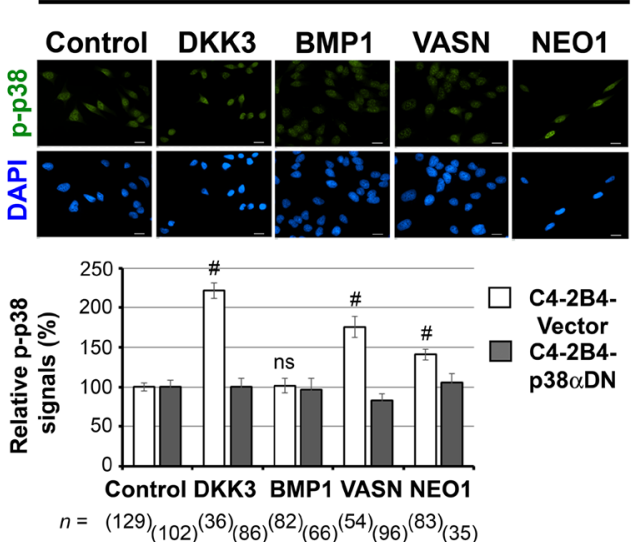

C

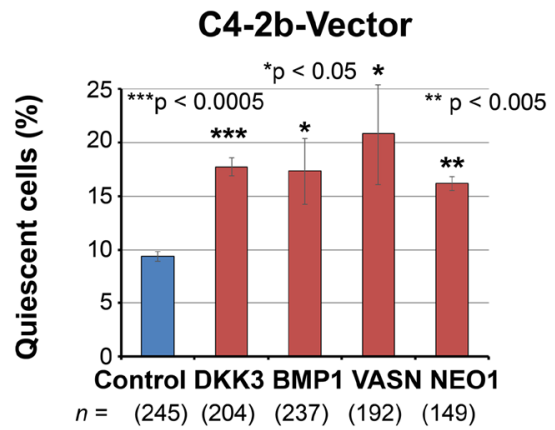

C4-2b-p38 $\alpha$ DN

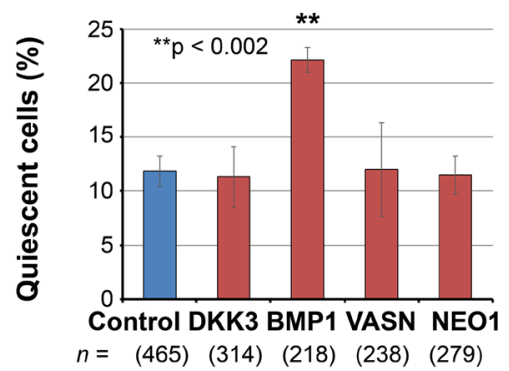

D

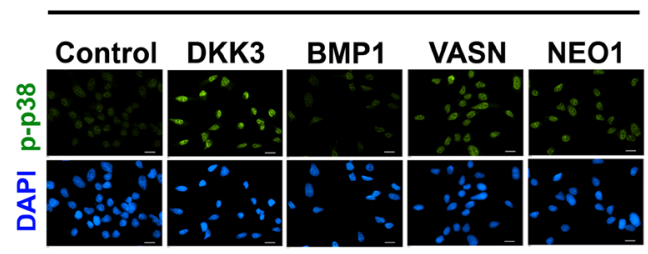

C4-2b-p38 $\alpha$ DN
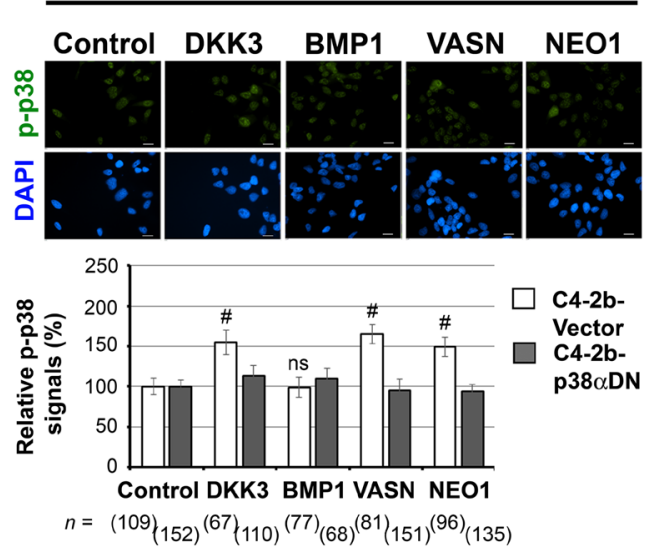

Figure 6. Dominant-negative p38 $\alpha$ MAPK prevents dormancy induction in vitro for DKK3, VASN and NEO1, but not BMP1. (A) C4-2B4 cells stably-expressing empty vector or $\mathrm{p} 38 \alpha \mathrm{DN}$ mutant were treated with the indicated factors for $72 \mathrm{~h}$ and analyzed by live-cell imaging. Quantification of \% quiescent cells that did not divide over $72 \mathrm{~h}$ relative to total cells examined (mean \pm s.e.m.). $n$, number of cells monitored. $\mathrm{N}$, number of independent experiments for C4-2B4-Vector cells: control $(\mathrm{N}=4)$, DKK3 $(\mathrm{N}=4)$, BMP1 $(\mathrm{N}=3)$, vasorin $(\mathrm{N}=3)$, neogenin $(\mathrm{N}=3)$; and for C4-2B4-p38 $\alpha \mathrm{DN}$ cells: control $(\mathrm{N}=5)$, DKK3 $(\mathrm{N}=6)$, BMP1 $(\mathrm{N}=3)$, vasorin $(\mathrm{N}=3)$, neogenin $(\mathrm{N}=3)$. P values were by $t$ test. (B) Cells in $(A)$ were treated with the indicated factors for $3 \mathrm{~h}$ and immunostained for p-p38 (upper and middle). All bars, $20 \mu \mathrm{m}$. Relative p-p38 signals in the nucleus of factor-treated cells compared to those in control cells (lower). $n$, number of nuclei analyzed. P values were by $t$ test. ${ }^{*} \mathrm{p}<0.0001$; ns, not significant. (C) C4-2b-Vector or C4-2b-p38 $\alpha$ DN cells were treated as in (A), and \% cellular quiescence was analyzed by live-cell imaging. $n$, number of cells monitored. $\mathrm{N}$, number of independent experiments for $\mathrm{C} 4-2 \mathrm{~b}-$ Vector cells: control $(\mathrm{N}=3)$, DKK3 $(\mathrm{N}=3)$, BMP1 $(\mathrm{N}=3)$, vasorin $(\mathrm{N}=3)$, neogenin $(\mathrm{N}=2)$; and for $\mathrm{C} 4-2 \mathrm{~b}$ p38 $\alpha$ DN cells: control $(\mathrm{N}=6)$, DKK3 $(\mathrm{N}=5), \mathrm{BMP} 1(\mathrm{~N}=3)$, vasorin $(\mathrm{N}=3)$, neogenin $(\mathrm{N}=3)$. P values were by $t$ test. (D) Cells in (C) were treated as in (B) and relative p-p38 signals in the nucleus were analyzed as in (B). 
enriched in the perisinusoidal vascular region. Thus, various dormancy-inducing factors secreted by different cell types within the tumor microenvironment are involved in the induction of tumor cell dormancy.

We have previously performed proteomics analysis of osteoblast exosomes, which we termed osteosomes, isolated from undifferentiated/proliferating versus differentiated/mineralizing primary mouse osteoblasts ${ }^{67}$. It is possible that the proteomics analysis of Calvarial-CM contains both bone-secreted soluble factors and proteins derived from osteosomes. We compared the 132 secreted proteins identified in Bone-CM (Table 1) with the 373 proteins previously identified in osteosomes ${ }^{67}$. We found that 25 proteins $(18.9 \%)$ in the Bone-CM were also found in osteosomes (Supplemental Table S3). These include the cytokine MIF; chemokines S10A9, S10AB and S10A6; ECM glycoproteins TENN, AEBP1 and LAMB1; and ECM regulator proteins SERPH, MMP13, CD109, CATB and A2MP (Supplemental Table S3). Notably, the bone-secreted factors DKK3, BMP1, vasorin, neogenin, MIA and NGAL that exhibited dormancy-inducing activity in PCa cells are not found in the osteosomes. Whether osteosomal proteins can mediate dormancy induction in PCa cells remains to be determined.

Only a limited number of signaling pathways that mediate dormancy responses have been reported. A change in mitogenic signaling from the Ras-induced extracellular signal-regulated kinase (ERK) pathway to the p38MAPK pathway has been shown to lead to a switch from proliferation to cellular dormancy ${ }^{68-70}$. Our studies together with reports by others showed that the p38MAPK signaling pathway is involved in PCa cell quiescence mediated by TGF32, GDF10, BMP7, DKK3, vasorin and neogenin (Figs. 5 and 6) ) $^{3,14,50}$. Interestingly, we note that factors that elicited a more sustained p-p38MAPK activation and nuclear translocation for up to $24-48 \mathrm{~h}$, such as DKK3 and vasorin, generated a higher level of dormancy induction than those that generated a transient p-p38MAPK response, such as neogenin, in PCa cells (Fig. 5). While the significance of the different kinetics of p38MAPK activation is currently unclear, they may have effects on the duration of the dormancy state. How p38MAPK activation imparts specificity to dormancy induction is also unknown. In our previous study, we found that p38MAPK phosphorylates RB at the novel N-terminal S249/T252 sites $^{71}$ to block PCa cell proliferation, a process that leads to an increase in the cell cycle CDK inhibitor p27, followed by G0-G1 cell cycle arrest and cellular quiescence ${ }^{3}$. While $\mathrm{p} 38 \mathrm{MAPK}$ represents a canonical dormancy signaling pathway, other pathways that signal to cellular dormancy also exist. Johnson et al. ${ }^{58}$ reported that the leukemia inhibiting factor LIF, a member of the IL-6 cytokine family, induces breast cancer cell dormancy by activating STAT3 signaling molecules. Notably, we found that BMP-1 induces cellular dormancy through a p38MAPK-independent pathway (Fig. 6), which remains to be identified.

How dormancy-inducing factors regulate the dormancy gene network is not clear. Aguirre-Ghiso ${ }^{72}$ and Segall's ${ }^{73}$ groups have reported that $\mathrm{p} 38 \mathrm{MAPK}$ signaling reprograms tumor cells to acquire a quiescence program through regulating a network of transcription factors and target genes ("dormancy signature genes") whose expression promotes quiescence of metastatic head and neck squamous cell carcinoma HEp3 cells and breast cancer cells, respectively. These genes constitute a dormancy transcription network that confers cellular dormancy. The transcription factors include NR2F1/COUPTF1 ${ }^{73,74}$, BHLHE41/Dec2/Sharp- $1^{14,73}$ and FOXM1 $1^{72,73}$, which may serve as a "switch" for converting active tumor cells into "dormant" cells. BHLHE41 has been shown to suppress the metastasis of aggressive triple-negative breast cancers through the degradation of hypoxia inducing factor HIF that promotes tumor angiogenesis ${ }^{75,76}$. How p38MAPK signaling leads to BHLHE41 gene expression and which dormancy signature genes might be regulated by BHLHE41 in PCa cells remain to be elucidated.

Delineating the mechanisms that lead to exit from dormancy is important for preventing tumor relapse. Similar to dormancy entry, dormancy exit can be due to intrinsic properties of the tumor cells that overcome dormancy and/or extrinsic signals encountered in the tumor microenvironment ${ }^{77,78}$. An increase in the expression of the BMP inhibitor Coco has been shown to render highly metastatic MDA-MB-231 breast cancer cells non-dormant ${ }^{79}$ as well as to promote metastatic outgrowth of $4 \mathrm{TO} 7$ mammary tumor cells in lung by inhibit-ing $\mathrm{BMP}$ signaling, thus allowing the reactivation of tumor cells from dormancy ${ }^{79}$. Increased expression of VCAM1 in mammary tumor cells has been shown to induce bone lysis, resulting in the release of growth factors from bone that enable tumor cells to exit dormancy ${ }^{4,80}$. Increased signaling through $\beta 1$ integrin was shown to induce both D2A1 breast cancer cells ${ }^{48}$ and LuCaP PDX PCa cells ${ }^{81}$ to transition from quiescence to proliferation. Additionally, alterations in the tumor microenvironment as a result of hormonal changes, aging or therapies ${ }^{77,78}$ may lead to a loss of dormancy-inducing factors. Together, these observations suggest that entry into and exit out of cellular dormancy may involve distinct pathways.

Currently, therapy strategies that target dormant tumor cells, which are resistant to chemotherapies ${ }^{82,83}$, are limited ${ }^{77,83}$. It seems that keeping dormant tumor cells dormant indefinitely or eradicating dormant tumor cells while they are dormant would be safer than reactivation followed by chemotherapy. In this context, maintaining the dormancy-conferring microenvironment would be an important aspect of the prevention strategy. Identification of mechanisms that support tumor cell survival during prolonged periods of dormancy may elucidate strategies to target dormant tumor cells. Because dormant tumor cells are responsible for cancer relapse, further understanding of tumor cell dormancy mechanisms is warranted.

\section{Materials and Methods}

Cell lines, reagents and antibodies. Human PCa C4-2B4 (gift from Robert Sikes, University of Delaware) ${ }^{53,54}$ and C4-2b (gift from Leland Chung, Cedars-Sinai Medical Center) ${ }^{52}$ were used. C4-2B4 and C4-2b cells transduced with either $\mathrm{pBMN}-\mathrm{I}-\mathrm{GFP}$ Vector alone or retroviral-expressing dominant-negative p38 $\alpha \mathrm{MAPK}$ $(\mathrm{p} 38 \alpha \mathrm{DN})$ mutant, containing mutations (Thr180-Gly-Tyr182 to Ala180-Gly-Phe182) in the activation loop between the two kinase domains ${ }^{84}$, were as previously described ${ }^{3}$. The identity of all cell lines was verified by polymorphic Short Tandem Repeat loci (STR) profiling, and all cell lines are mycoplasma free. Human recombinant proteins DKK3, BMP1, Neogenin (R\&D); Vasorin (Novoprotein); MIA (Peprotech); NGAL, PEDF (SinoBiologicals); and BMP7 (Prospec) were obtained from commercial sources. Antibodies for Ki67 (Dako \#MIB-1), p27Kip1 (Cell Signaling \#D69C12), phospho-p38MAPK (Thr180/Tyr182) (Cell Signaling \#4511), 
DKK3 (Proteintech \#10355-1-AP), BMP1 (abcam \#ab205394), MIA (Santa Cruz \#sc-37735), NGAL (Santa Cruz \#sc-515876), and PEDF (R\&D \#AF-1177) were obtained from commercial sources.

Conditioned media from mouse calvariae (Calvarial-CM) and primary mouse osteoblast preparation. Calvariae were prepared from 20 2-5 day-old pups and incubated in BGJb medium, a chemically-defined media designed for the growth of fetal rat long bones (Thermo Fisher), and supplemented with $0.1 \%$ BSA as previously described ${ }^{12}$. Conditioned media from two independent batches of calvariae were prepared at $48 \mathrm{~h}$ (Calvarial-CM \#1 and Calvarial-CM \#2) and used for dormancy and ELISA assays. To prepare conditioned media for mass spectrometry analysis, calvariae were incubated in BSA-free BGJb medium for $48 \mathrm{~h}$ (Bone-CM). Two independent Bone-CM1 and Bone-CM2 were prepared. Primary mouse osteoblasts (PMOs) were prepared as follows. Calvariae from $\sim 35$ new born pups were digested in $\alpha$-MEM containing $0.1 \mathrm{mg} / \mathrm{ml} \mathrm{col-}$ lagenase $\mathrm{P}$ and $0.25 \% \operatorname{trypsin}^{11}$. The first two digestions $(15 \mathrm{~min}$ each) that contained fibroblasts and other undefined cell types were discarded. After the third digestion $\left(37^{\circ} \mathrm{C}\right.$ for $\left.1 \mathrm{~h}\right)$, supernatant enriched in PMOs together with the calvariae pieces were plated in $\alpha$-MEM supplemented with $10 \%$ FBS for 3 to 4 days. The calvariae pieces were then removed and discarded. The cultures were then trypsinized and the PMOs were plated on $10 \mathrm{~cm}$ plates. All animal experiments in this work were conducted in accordance with NIH guidelines and have been approved by the institutional review board at the U. Texas M. D. Anderson Cancer Center.

Identification of proteins in bone-conditioned media by liquid chromatography-tandem mass spectrometry (LC-MS/MS). The Bone-CM samples were concentrated 20-fold in Centricon-10 (Millipore). The concentrated samples were precipitated by acetone (acetone/sample 5:1) and placed at $-20^{\circ} \mathrm{C}$ overnight. The precipitated proteins were resuspended in $10 \mu \mathrm{L}$ of Rapigest $(2 \mathrm{mg} / \mathrm{mL}$ in $100 \mathrm{mM}$ ammonium bicarbonate) (Waters) plus $30 \mu \mathrm{L}$ of $50 \mathrm{mM}$ ammonium bicarbonate, and denatured by heating to $100^{\circ} \mathrm{C}$ for $10 \mathrm{~min}$. The denatured samples were cooled to room temperature and digested with 200-400 ng sequencing-grade trypsin ( $20 \mathrm{ng} / \mu \mathrm{L}$ in $0.02 \%$ formic acid) (Promega) at $37^{\circ} \mathrm{C}$ overnight. The digested samples were dried down using Speedvac and reconstituted in $1 \%$ formic acid. The resulting peptides were analyzed by liquid chromatography-tandem mass spectrometry (LC-MS/MS) on an Orbitrap Elite mass spectrometer (Thermo Scientific) as previously described ${ }^{67}$. HPLC analyses were performed with Dionex Ultimate 3000 . Samples were injected into a Phenomenex core-shell C18 DB column $(2.7 \mu \mathrm{m} 15 \mathrm{~cm})$, with mobile phase compositions of A: $0.1 \%$ formic acid in water and B: $0.1 \%$ formic acid in acetonitrile and with a flow rate of $100 \mu \mathrm{L} / \mathrm{min}$. The gradient was held isocratic at $2 \% \mathrm{~B}$ for $2 \mathrm{~min}$, ramped up to $35 \%$ at $105 \mathrm{~min}$, ramped up to $80 \%$ at $106 \mathrm{~min}$, maintained at $80 \%$ until $110 \mathrm{~min}$, ramped down to $2 \%$ at $110.1 \mathrm{~min}$, and held at $2 \%$ until $120 \mathrm{~min}$.

The MS parameters and scan strategy were: (a) mass range for MS1: 400-1300; (b) mass resolution for MS1: 500 000; (c) mass window for precursor ion selection: $0.5 \mathrm{~d}$; (d) number or precursors selected for tandem MS in each scan cycle: maximum in $2 \mathrm{~s}$; (e) mass analyzer for tandem-MS: MS1: Orbitrap; MS2: Iontrap; (f) charge state screening parameters: $2-4$; (g) relative collision energy: 30\%; (h) dynamic exclusion settings: $15 \mathrm{~s}$.

Data processing of the MS results were as follows: (a) Database: SwissProt_2018_02 Mus database (17 024 sequences), Total sequences: 556 825, Total residues: 199652 254; (b) Search engine: Mascot 2.6 via Proteome Discoverer 1.4; (c) Precursor and product ion mass tolerances: Peptide Mass Tolerance: 10 ppm, Fragment Mass Tolerance: $0.8 \mathrm{Da}$; Use average precursor mass: False; (d) Peptide scoring options: Peptide Cut Off Score: 10, Peptide Without Protein Cut Off Score: 5; (e) Protein scoring options: MudPIT Scoring: False, Protein Relevance Threshold: 20, Protein Relevance Factor: 1; (f) Enzyme specificity: Trypsin, 2 missed cleavages allowed; (g) Dynamic modifications: Oxidation $(\mathrm{M})$, Gln $\rightarrow$ pyro-Glu (N-term Q), Trioxidation (C); (h) Method for false discovery rate (FDR) assessment: Processing node 7: Target Decoy PSM Validator; Decoy Database Search: Target FDR (strict): 0.01 .

Western blot analysis. A 20X concentrated preparation of BSA-free mouse Calvarial-CM (Bone-CM) along with a $20 \mathrm{X}$ concentrated control BGJb medium were analyzed by Western blot. NuPAGE MES SDS running buffer (ThermoFisher) was used to better resolve small to medium-size proteins. After gel transfer, the filters were cut into two pieces at either the 25 or $37 \mathrm{kDa}$ mark to accommodate the concurrent analysis of bone-secreted factors with large and small molecular sizes. The original Western blots are shown in Supplemental Fig. S1.

ELISA. Protein levels of bone-secreted factors in two independent mouse Calvarial-CM preparations were analyzed by ELISA as previously described ${ }^{12}$. ELISA kits (mouse) were from AVIVA System Biology for mBMP1 (OKCD02401) and mDKK3 (OKCD02498), and from MyBioSource for mNEO1 (MBS2533529) and mVasorin (MBS2706258).

Quantitative real-time RT-PCR (qRT-PCR). Total RNA was prepared from PMO or calvariae and analyzed by quantitative RT-PCR as previously described ${ }^{12}$, to examine the expression of bone-secreted factors. Mouse-specific primers are as listed (Table 3).

Live-cell time-lapse imaging. PCa cells were plated in Hi-Q4 glass-bottom dishes (Ibidi) and cultured in RPMI-1640 containing 10\% FBS. Cells were washed with RPMI- 1640 containing $0.1 \%$ FBS before the addition of Calvarial-CM or recombinant human proteins. Concentrations used for the various recombinant human proteins were empirically derived. Images (20X objective) were acquired every $20 \mathrm{~min}$ for $72 \mathrm{~h}$ in a BioStation (Nikon) as previously described ${ }^{3}$. Data were compiled using NIS-Elements (Nikon) software.

Immunofluorescence imaging. Immediately following live-cell recording, cells were fixed and permeabilized, incubated with anti-Ki67 mouse monoclonal antibody (1:1000) or co-incubated with anti-Ki67 and anti-p27 rabbit monoclonal antibody (1:700) overnight, followed by goat-anti-mouse IgG-Alexa Fluor 488 and 


\begin{tabular}{|c|c|}
\hline Mouse BMP1-Forward & AGTTTGGCATCGTGGTCCAT \\
\hline Mouse BMP1-Reverse & TACTCCTGCCCTGGCTGTAT \\
\hline Mouse BMP7-Forward & CGTCCAGACACTGGTTCACTT \\
\hline Mouse BMP7-Reverse & GAGGACAGAGATGGCGTTGA \\
\hline Mouse DKK3-Forward & TTGTTCATTCGAATTGGGCGG \\
\hline Mouse DKK3-Reverse & ACACAGCAAAATACCCCCGA \\
\hline Mouse LECT1-Forward & TTACCACCAGCAGGAAGGAG \\
\hline Mouse LECT1-Reverse & GTAGCCTCCCAGTGGTTCAC \\
\hline Mouse MIA-Forward & GTCCATGATGGTGTGGTCCC \\
\hline Mouse MIA-Reverse & TGGAGATAGGATGGCTGCATTC \\
\hline Mouse NGAL-Forward & ATGCACAGGTATCCTCAGGT \\
\hline Mouse NGAL-Reverse & TGGCGAACTGGTTGTAGTCC \\
\hline Mouse NEO1-Forward & CTCACACAGTGCCAGATCCC \\
\hline Mouse NEO1-Reverse & ATGTTGGTCTTCCACCGGAC \\
\hline Mouse PEDF-Forward & CTACAGAACCCCCAGAGGGA \\
\hline Mouse PEDF-Reverse & AAGCAGAGCCCGTTCATGTT \\
\hline Mouse TGF $\beta 1$-Forward & AGCTGCGCTTGCAGAGATTA \\
\hline Mouse TGF $\beta 1$-Reverse & AGCCCTGTATTCCGTCTCCT \\
\hline Mouse TGF $\beta 2$-Forward & AATGGCTCTCCTTCGACGTG \\
\hline Mouse TGF 32 -Reverse & AGGTGCCATCAATACCTGCAA \\
\hline Mouse VASN-Forward & GAGGTGAAGGACTGAGGCCC \\
\hline Mouse VASN-Reverse & CTTCTGTCCCAGGAGACGACTG \\
\hline Human/mouse GAPDH-Forward & CCCAGAAGACTGTGGATG \\
\hline Human/mouse GAPDH-Reverse & GCAGGGATGATGTTCTGG \\
\hline
\end{tabular}

Table 3. PCR primers used for bone-secreted factors.

goat-anti-rabbit IgG-Texas Red (ThermoFisher) secondary antibodies for $3 \mathrm{~h}$, and re-imaged on the BioStation ${ }^{3}$. PCa cells were also incubated with various bone-secreted factors over a time course, followed by immunostaining with phospho-p38MAPK (1:200) antibody overnight and counter-staining with DAPI for DNA. Images were acquired on a TE2000 widefield microscope system (Nikon, Lewisville, TX). The level of phospho-p38MAPK fluorescence per nucleus was quantified using NIS-Elements 5.11.01 (Nikon) software.

Statistical analysis. Data quantification was performed by using the Student's $t$-test and expressed as mean \pm s.e.m. $P$ values of $<0.05$ were considered statistically significant.

Received: 1 September 2019; Accepted: 12 November 2019;

Published online: 09 December 2019

\section{References}

1. Logothetis, C. J. \& Lin, S. H. Osteoblasts in prostate cancer metastasis to bone. Nat Rev Cancer 5, 21-28 (2005).

2. Ahove, D. A. et al. Which patients with undetectable PSA levels 5 years after radical prostatectomy are still at risk of recurrence?-implications for a risk-adapted follow-up strategy. Urology 76, 1201-1205 (2010).

3. Yu-Lee, L.-Y. et al. Osteoblast-Secreted Factors Mediate Dormancy of Metastatic Prostate Cancer in the Bone via Activation of the TGFbetaRIII-p38MAPK-pS249/T252RB Pathway. Cancer Res 78, 2911-2924 (2018).

4. Esposito, M., Guise, T. \& Kang, Y. The Biology of Bone Metastasis. Cold Spring Harb Perspect Med 8, a031252- (2018).

5. Croucher, P. I., McDonald, M. M. \& Martin, T. J. Bone metastasis: the importance of the neighbourhood. Nat Rev Cancer 16, 373-386 (2016).

6. Lawson, M. A. et al. Osteoclasts control reactivation of dormant myeloma cells by remodelling the endosteal niche. Nat Commun 6 , 8983-8998 (2015).

7. Wang, N. et al. Prostate cancer cells preferentially home to osteoblast-rich areas in the early stages of bone metastasis: evidence from in vivo models. J Bone Miner Res 29, 2688-2696 (2014).

8. Ren, D. et al. Wnt5a induces and maintains prostate cancer cells dormancy in bone. J Exp Med 216, 428-449 (2018).

9. Shiozawa, Y. et al. GAS6/AXL axis regulates prostate cancer invasion, proliferation, and survival in the bone marrow niche. Neoplasia 12, 116-127 (2010).

10. Mishra, A. et al. Hypoxia stabilizes GAS6/Axl signaling in metastatic prostate cancer. Mol Cancer Res 10, 703-712 (2012).

11. Yang, J. et al. Prostate cancer cells induce osteoblast differentiation through a Cbfa1-dependent pathway. Cancer Res 61, 5652-5659 (2001).

12. Lin, S. H. et al. A 45-kDa ErbB3 secreted by prostate cancer cells promotes bone formation. Oncogene 27, 5195-5203 (2008).

13. Aguirre-Ghiso, J. A. Models, mechanisms and clinical evidence for cancer dormancy. Nat Rev Cancer 7, 834-846 (2007).

14. Bragado, P. et al. TGF-beta2 dictates disseminated tumour cell fate in target organs through TGF-beta-RIII and p38alpha/beta signalling. Nat Cell Biol 15, 1351-1361 (2013).

15. Naba, A. et al. The extracellular matrix: Tools and insights for the "omics" era. Matrix Biol 49, 10-24 (2016).

16. Naba, A. et al. Characterization of the Extracellular Matrix of Normal and Diseased Tissues Using Proteomics. J Proteome Res 16, 3083-3091 (2017).

17. Naba, A. et al. Extracellular matrix signatures of human primary metastatic colon cancers and their metastases to liver. BMC Cancer 14, 518-529 (2014). 
18. Glavey, S. V. et al. Proteomic characterization of human multiple myeloma bone marrow extracellular matrix. Leukemia 31, 2426-2434 (2017).

19. Ouni, E., Vertommen, D., Chiti, M. C., Dolmans, M. M. \& Amorim, C. A. A draft map of the human ovarian proteome for tissue engineering and clinical applications. Mol Cell Proteomics 18, S159-S173 (2018).

20. Ghajar, C. M. et al. The perivascular niche regulates breast tumour dormancy. Nat Cell Biol 15, 807-817 (2013).

21. Naba, A., Clauser, K. R., Mani, D. R., Carr, S. A. \& Hynes, R. O. Quantitative proteomic profiling of the extracellular matrix of pancreatic islets during the angiogenic switch and insulinoma progression. Sci Rep 7, 40495- (2017).

22. Ragelle, H. et al. Comprehensive proteomic characterization of stem cell-derived extracellular matrices. Biomaterials 128, 147-159 (2017).

23. Zenzmaier, C. et al. Dysregulation of Dkk-3 expression in benign and malignant prostatic tissue. Prostate 68, 540-547 (2008)

24. Kawano, Y. et al. Regulation of prostate cell growth and morphogenesis by Dickkopf-3. Oncogene 25, 6528-6537 (2006).

25. Romero, D. et al. Dickkopf-3 regulates prostate epithelial cell acinar morphogenesis and prostate cancer cell invasion by limiting TGF-beta-dependent activation of matrix metalloproteases. Carcinogenesis 37, 18-29 (2016).

26. Sakaguchi, M. et al. Overexpression of REIC/Dkk-3 in normal fibroblasts suppresses tumor growth via induction of interleukin-7. J Biol Chem 284, 14236-14244 (2009).

27. Blesch, A. et al. Cloning of a novel malignant melanoma-derived growth-regulatory protein, MIA. Cancer Res 54, 5695-5701 (1994).

28. Schubert, T. et al. Modulation of cartilage differentiation by melanoma inhibiting activity/cartilage-derived retinoic acid-sensitive protein (MIA/CD-RAP). Exp Mol Med 42, 166-174 (2010).

29. Schmidt-Ott, K. M. et al. Dual action of neutrophil gelatinase-associated lipocalin. J Am Soc Nephrol 18, 407-413 (2007).

30. Hagihara, M. et al. Neogenin, a receptor for bone morphogenetic proteins. J Biol Chem 286, 5157-5165 (2011).

31. Tian, C. \& Liu, J. Repulsive guidance molecules (RGMs) and neogenin in bone morphogenetic protein (BMP) signaling. Mol Reprod Dev 80, 700-717 (2013)

32. Zhou, Z. et al. Neogenin regulation of BMP-induced canonical Smad signaling and endochondral bone formation. Dev Cell 19, 90-102 (2010).

33. Tian, C. et al. The neogenin/DCC homolog UNC-40 promotes BMP signaling via the RGM protein DRAG-1 in C. elegans. Development 140, 4070-4080 (2013).

34. Mera, H. et al. Chondromodulin-1 directly suppresses growth of human cancer cells. BMC Cancer 9, 166-177 (2009).

35. Ikeda, Y. et al. Vasorin, a transforming growth factor beta-binding protein expressed in vascular smooth muscle cells, modulates the arterial response to injury in vivo. Proc Natl Acad Sci USA 101, 10732-10737 (2004).

36. Lin, S. C. et al. Endothelial-to-Osteoblast Conversion Generates Osteoblastic Metastasis of Prostate Cancer. Dev Cell 41, 467-480 (2017).

37. Wozney, J. M. et al. Novel regulators of bone formation: molecular clones and activities. Science 242, 1528-1534 (1988).

38. Muir, A. \& Greenspan, D. S. Metalloproteinases in Drosophila to humans that are central players in developmental processes. J Biol Chem 286, 41905-41911 (2011).

39. Dawson, D. W. et al. Pigment epithelium-derived factor: a potent inhibitor of angiogenesis. Science 285, 245-248 (1999).

40. Li, F., Song, N., Tombran-Tink, J. \& Niyibizi, C. Pigment epithelium derived factor suppresses expression of Sost/Sclerostin by osteocytes: implication for its role in bone matrix mineralization. J Cell Physiol 230, 1243-1249 (2015).

41. Xu, J. et al. Exogenous DKK-3/REIC inhibits Wnt/beta-catenin signaling and cell proliferation in human kidney cancer KPK1. Oncol Lett 14, 5638-5642 (2017)

42. Grgurevic, L. et al. Circulating bone morphogenetic protein 1-3 isoform increases renal fibrosis. J Am Soc Nephrol 22, 681-692 (2011).

43. Li, S. et al. Vasorin is a potential serum biomarker and drug target of hepatocarcinoma screened by subtractive-EMSA-SELEX to clinic patient serum. Oncotarget 6, 10045-10059 (2015).

44. Zhong, S., Zou, L., Zhao, Y., Hu, B. \& Xie, H. Effects of different concentrations of neogenin on proliferation, apoptosis and related proliferative factors in human trophoblasts. J Huazhong Univ Sci Technol 30, 500-504 (2010).

45. Stoll, R. et al. The extracellular human melanoma inhibitory activity (MIA) protein adopts an SH3 domain-like fold. EMBO J 20, 340-349 (2001).

46. Nymo, S. H. et al. Serum neutrophil gelatinase-associated lipocalin (NGAL) concentration is independently associated with mortality in patients with acute coronary syndrome. Int J Cardiol 262, 79-84 (2018).

47. Li, F., Song, N., Tombran-Tink, J. \& Niyibizi, C. Pigment epithelium-derived factor enhances differentiation and mineral deposition of human mesenchymal stem cells. Stem Cells 31, 2714-2723 (2013).

48. Barkan, D. et al. Inhibition of metastatic outgrowth from single dormant tumor cells by targeting the cytoskeleton. Cancer Res 68, 6241-6250 (2008).

49. El Touny, L. H. et al. Combined SFK/MEK inhibition prevents metastatic outgrowth of dormant tumor cells. J Clin Invest 124, 156-168 (2014)

50. Kobayashi, A. et al. Bone morphogenetic protein 7 in dormancy and metastasis of prostate cancer stem-like cells in bone. J Exp Med 208, 2641-2655 (2011)

51. Muir, A. M. et al. Induced ablation of Bmp1 and Tll1 produces osteogenesis imperfecta in mice. Hum Mol Genet 23, 3085-3101 (2014).

52. Thalmann, G. N. et al. Androgen-independent cancer progression and bone metastasis in the LNCaP model of human prostate cancer. Cancer Res 54, 2577-2581 (1994).

53. Wu, T. T. et al. Establishing human prostate cancer cell xenografts in bone: induction of osteoblastic reaction by prostate-specific antigen-producing tumors in athymic and SCID/bg mice using LNCaP and lineage-derived metastatic sublines. Int J Cancer 77, 887-894 (1998).

54. Thalmann, G. N. et al. LNCaP progression model of human prostate cancer: androgen-independence and osseous metastasis. Prostate 44, 91-103 (2000).

55. Zhang, W. et al. Targeting the MYCN-PARP-DNA Damage Response Pathway in Neuroendocrine Prostate Cancer. Clin Cancer Res 24, 696-707 (2018)

56. Sosa, M. S., Avivar-Valderas, A., Bragado, P., Wen, H. C. \& Aguirre-Ghiso, J. A. ERK1/2 and p38alpha/beta signaling in tumor cell quiescence: opportunities to control dormant residual disease. Clin Cancer Res 17, 5850-5857 (2011).

57. Prunier, C., Baker, D., Ten, D. P. \& Ritsma, L. TGF-beta Family Signaling Pathways in Cellular Dormancy. Trends Cancer 5, 66-78 (2019).

58. Johnson, R. W. et al. Induction of LIFR confers a dormancy phenotype in breast cancer cells disseminated to the bone marrow. Nat Cell Biol 18, 1078-1089 (2016).

59. Hamzehzadeh, L., Caraglia, M., Atkin, S. L. \& Sahebkar, A. Dickkopf homolog 3 (DKK3): A candidate for detection and treatment of cancers? J Cell Physiol 233, 4595-4605 (2018).

60. Kardooni, H. et al. CRISPR-Mediated Reactivation of DKK3 Expression Attenuates TGF-beta Signaling in Prostate Cancer. Cancers (Basel) 10, E165- (2018)

61. Hsieh, S. Y., Hsieh, P. S., Chiu, C. T. \& Chen, W. Y. Dickkopf-3/REIC functions as a suppressor gene of tumor growth. Oncogene 23, 9183-9189 (2004)

62. Veeck, J. \& Dahl, E. Targeting the Wnt pathway in cancer: the emerging role of Dickkopf-3. Biochim Biophys Acta 1825, 18-28 (2012). 
63. Mori, Y. et al. Identification of a progenitor cell population destined to form fracture fibrocartilage callus in Dickkopf-related protein 3-green fluorescent protein reporter mice. J Bone Miner Metab 34, 606-614 (2016).

64. Malapeira, J., Esselens, C., Bech-Serra, J. J., Canals, F. \& Arribas, J. ADAM17 (TACE) regulates TGFbeta signaling through the cleavage of vasorin. Oncogene 30, 1912-1922 (2011).

65. Annes, J. P., Munger, J. S. \& Rifkin, D. B. Making sense of latent TGFbeta activation. J Cell Sci 116, 217-224 (2003).

66. Price, T. T. et al. Dormant breast cancer micrometastases reside in specific bone marrow niches that regulate their transit to and from bone. Sci Transl Med 8, 340ra73- (2016).

67. Bilen, M. A. et al. Proteomics Profiling of Exosomes from Primary Mouse Osteoblasts under Proliferation versus Mineralization Conditions and Characterization of Their Uptake into Prostate Cancer Cells. J Proteome Res 16, 2709-2728 (2017).

68. Aguirre-Ghiso, J. A., Liu, D., Mignatti, A., Kovalski, K. \& Ossowski, L. Urokinase receptor and fibronectin regulate the ERK(MAPK) to p38(MAPK) activity ratios that determine carcinoma cell proliferation or dormancy in vivo. Mol Biol Cell 12, 863-879 (2001).

69. Aguirre-Ghiso, J. A., Estrada, Y., Liu, D. \& Ossowski, L. ERK(MAPK) activity as a determinant of tumor growth and dormancy; regulation by p38(SAPK). Cancer Res 63, 1684-1695 (2003).

70. Ranganathan, A. C., Adam, A. P. \& Aguirre-Ghiso, J. A. Opposing roles of mitogenic and stress signaling pathways in the induction of cancer dormancy. Cell Cycle 5, 1799-1807 (2006).

71. Gubern, A. et al. The N-Terminal Phosphorylation of RB by p38 Bypasses Its Inactivation by CDKs and Prevents Proliferation in Cancer Cells. Mol Cell 64, 25-36 (2016).

72. Adam, A. P. et al. Computational identification of a p38SAPK-regulated transcription factor network required for tumor cell quiescence. Cancer Res 69, 5664-5672 (2009).

73. Kim, R. S. et al. Dormancy signatures and metastasis in estrogen receptor positive and negative breast cancer. PLoS One 7, e35569 (2012).

74. Sosa, M. S. et al. NR2F1 controls tumour cell dormancy via SOX9- and RARbeta-driven quiescence programmes. Nat Commun 6, 6170- (2015).

75. Piccolo, S., Enzo, E. \& Montagner, M. p63, Sharp1, and HIFs: master regulators of metastasis in triple-negative breast cancer. Cancer Res 73, 4978-4981 (2013).

76. Amelio, I. \& Melino, G. The "Sharp" blade against HIF-mediated metastasis. Cell Cycle 11, 4530-4535 (2012).

77. Linde, N., Fluegen, G. \& Aguirre-Ghiso, J. A. The Relationship Between Dormant Cancer Cells and Their Microenvironment. Adv Cancer Res 132, 45-71 (2016).

78. Byrne, N. M., Summers, M. A. \& McDonald, M. M. Tumor Cell Dormancy and Reactivation in Bone: Skeletal Biology and Therapeutic Opportunities. JBMR Plus 3, e10125 (2019).

79. Gao, H. et al. The BMP inhibitor Coco reactivates breast cancer cells at lung metastatic sites. Cell 150, 764-779 (2012).

80. Lu, X. et al. VCAM-1 promotes osteolytic expansion of indolent bone micrometastasis of breast cancer by engaging alpha4beta1positive osteoclast progenitors. Cancer Cell 20, 701-714 (2011)

81. Ruppender, N. et al. Cellular Adhesion Promotes Prostate Cancer Cells Escape from Dormancy. PLoS One 10, e0130565 (2015).

82. Brown, J. A. et al. TGF-beta-Induced Quiescence Mediates Chemoresistance of Tumor-Propagating Cells in Squamous Cell Carcinoma. Cell Stem Cell 21, 650-664 (2017).

83. Recasens, A. \& Munoz, L. Targeting Cancer Cell Dormancy. Trends Pharmacol Sci 40, 128-141 (2019).

84. Somwar, R. et al. A dominant-negative p38 MAPK mutant and novel selective inhibitors of p38 MAPK reduce insulin-stimulated glucose uptake in 3T3-L1 adipocytes without affecting GLUT4 translocation. J Biol Chem 277, 50386-50395 (2002).

\section{Acknowledgements}

This work was supported by grants from the NIH (CA174798, 5P50 CA140388, P30 CA16672), the Prostate Cancer Foundation, Cancer Prevention and Research Institute of Texas (CPRIT RP150179, RP190252), and funds from The University of Texas MD Anderson Sister Institute Network Fund and Moon Shot Program.

\section{Author contributions}

L.-Y.Y.-L., Y.-C.L. and S.-H.L. designed the research; L.-Y.Y.-L., Y.-C.L., J.P., G.Y. and S.-C.L. performed the experiments; L.-Y.Y.-L., Y.-C.L., J.P., T.P., D.H.H., B.-F.P. and S.-H.L. analyzed the data; L.-Y.Y.-L. and S.-H.L. wrote the paper.

\section{Competing interests}

The authors declare no competing interests.

\section{Additional information}

Supplementary information is available for this paper at https://doi.org/10.1038/s41598-019-54566-4.

Correspondence and requests for materials should be addressed to L.-Y.Y.-L. or S.-H.L.

Reprints and permissions information is available at www.nature.com/reprints.

Publisher's note Springer Nature remains neutral with regard to jurisdictional claims in published maps and institutional affiliations.

Open Access This article is licensed under a Creative Commons Attribution 4.0 International License, which permits use, sharing, adaptation, distribution and reproduction in any medium or format, as long as you give appropriate credit to the original author(s) and the source, provide a link to the Creative Commons license, and indicate if changes were made. The images or other third party material in this article are included in the article's Creative Commons license, unless indicated otherwise in a credit line to the material. If material is not included in the article's Creative Commons license and your intended use is not permitted by statutory regulation or exceeds the permitted use, you will need to obtain permission directly from the copyright holder. To view a copy of this license, visit http://creativecommons.org/licenses/by/4.0/.

(C) The Author(s) 2019 